\title{
The Present State of Art of Long Period Magnetotellurics in the Western Part of the Bohemian Massif
}

\author{
Václav Červ, Josef PeK, and Oldřich Praus \\ Geophysical Institute, Academy of Sciences of the Czech Republic, Bocni II/1401, \\ CZ-14131 Prague 4-Spořilov, Czech Republic
}

(Received November 5, 1996; Revised June 30, 1997; Accepted July 24, 1997)

\begin{abstract}
Research into the complex geological structure of the Middle European Variscides in the western part of the Bohemian Massif has largely intensified in connection with the KTB deep borehole project in the Oberpfalz, Germany. First results of long period magnetotelluric studies along an about $100 \mathrm{~km}$ long profile in SW Bohemia, close to the KTB drilling site, are presented here. They represent a partial step within a broader project of constructing a 3-D geoelectrical model of the western margin of the Bohemian Massif and resolving the relations of anomalous geoelectrical features to the geological structures of the region. The data roughly fit a composite model of a $2-\mathrm{D}$ regional structure, striking $\mathrm{E}-\mathrm{W}$, overlaid by a layer of highly distorting near-surface inhomogeneities. The distorting layer displays large anisotropy with preferred conductivity in NW-SE to NNW-SSE direction. Attempt is made to estimate the absolute static shift of the MT curves. Several variants of 2-D models for the deep regional structure are discussed, including an anisotropic model which can qualitatively explain the discrepancy of the principal directions indicated by the MT and GDS data. The relation of the results obtained along the particular profile to the regional geoelectrical background is studied.
\end{abstract}

\section{Introduction}

In several recent years an extensive geophysical and geological research has been carried out in the western part of the Bohemian Massif, mainly in connection with the 'Continental Deep Drilling Project' KTB in Oberpfalz, Germany. Anomalous geoelectrical effects observed in the immediate neighbourhood of the drilling site (e.g. Haak et al., 1991) were a strong motive for extending the deep geoelectrical research into a broader vicinity of that locality. On this account, two large projects of the regional geoelectrical studies were started in the western part of the Czech Republic after 1990.

The first one was organized by the Geofyzika Inc. Brno as a part of the national research program 'Geological model of the western part of the Bohemian Massif in relation to the ultradeep drill (KTB) in FRG', and represented a regional profile (see profile 1 in Fig. 1b), about $230 \mathrm{~km}$ in length, of $56 \mathrm{AMT}$ stations (frequency range from $1 \mathrm{kHz}$ to $1 / 128 \mathrm{~Hz}$ ) and 15 longperiod MT/GDS stations (period range from 1 to $4096 \mathrm{~s}$ ), measured and processed by the team of the Free University of Berlin (Klause et al., 1994). The investigations aimed at supplementing detailed geoelectrical information into the large and medium crustal depths for comparisons with the seismic reflection studies carried out along the identical profile (geotraverse 9HR) earlier.

The other project of the regional geoelectrical studies in West Bohemia, which will be mainly reported on in this contribution, was a profile of 14 long-period MT/GDS stations, about $100 \mathrm{~km}$ in length, arranged immediately along the Czech-German border (profile 2 in Fig. 1b). Besides the 14 basic long-period soundings (period range 10-4096 s), several additional AMT soundings were carried out at selected localities on the profile by teams of the University of Frankfurt, Germany, and cooperation teams from Italy (University of Padova, IIRG CNR Pisa). 

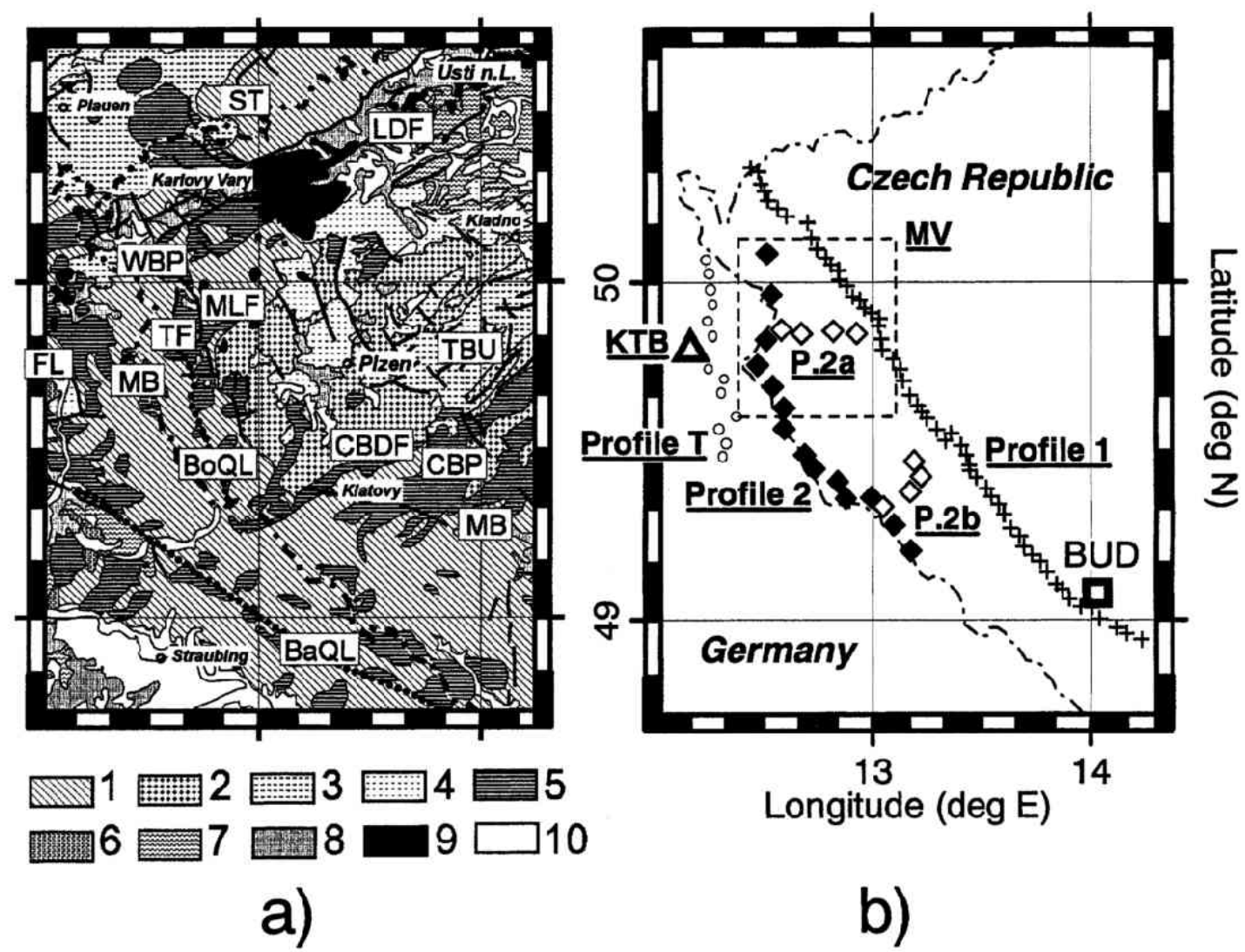

b)

Fig. 1. a) Schematic geological map of the western part of the Bohemian Massif. 1-crystalline schists, 2-Proterozoic, 3, 4-Paleozoic, 5-paleomagmatites, 6-Triassic, Jurrasic, 7-Cretaceous, 8-late Tertiary, 9-neovolcanites, 10-Quaternary; ST-Saxothuringicum, MB-Moldanubicum, TBU-Teplá-Barrandian unit, LDF--Litoměřice deep fault zone, WBP-West Bohemian Pluton, MLF-Mariánské Lázně deep fault, TF-Tachov fault, BoQL-Bohemian Quartz Lode, CBDF-Central Bohemian deep fault, CBP-Central Bohemian Pluton, FL-Franconian Line, BaQL-Bavarian Quartz Lode. b) Layout of the regional MT/GDS profiles in West Bohemia. KTB-location of the KTB borehole, Oberpfalz, Germany, BUD-the electromagnetic observatory Budkov in South Bohemia.

From the geological point of view, the broader German/Czech surroundings of the KTB site can be characterized as a region where different zones of the Bohemian Massif, representing the easternmost part of the European Hercynides, make contact (Suk et al., 1984). Specifically, the KTB drilling site is located near the western margin of the Bohemian Massif, and a few kilometers south of the structurally important boundary of the Moldanubian and Saxothuringian zones of the Central European orogenic belt. An exposed segment of the boundary, along which the two blocks of the earth crust collided about 320 million years ago and the Moldanubian rocks were overthrusted on the Saxothuringian ones, is believed to be the zone of Tirschenreuth and Mähring in the Oberpfalz, Germany. Its continuation into western Bohemia is assumed to be the Litoměrice fault zone, situated in the north of our interest region (Fig. 1a).

The region of the profile 2 represents a protrusion of the Moldanubian rocks towards the north, and is delineated by the Litoměrice fault zone in the north and by the Central Bohemian deep fault (suture) in the south. In the west, the region makes an immediate contact with the KTB 
area, with the Franconian Line as a significant western tectonic boundary. In the east, the West Bohemian fault zone separates the region under study from the Teplá-Barrandian Proterozoic unit.

On the regional scale, the present studies could draw on numerous previous large-scale geoelectrical investigations across the Variscean belt on the German territory. In particular, studies of Hofer (1990) and results of a long-period MT/GDS profiling presented by Eisel (1990) and Tauber (1993) have been largely used for comparisons with our data. Hofer's (1990) investigations aimed at resolving the geoelectrical structure across the suture zone between the Rhenohercynian and Saxothuringian blocks in the area of the Hessian Trough and the Mid German Crystalline High east of the Rhine Graben, about $200 \mathrm{~km}$ west of our target area. The data presented by Eisel (1990) and Tauber (1993) were collected along a N-S profile starting close to the south of the Mid German Crystalline High, in the Thuringian Basin, and ending in the Oberpfalz Forest Mts. in Bavaria. In its southern section (profile $\mathrm{T}$ in Fig. 1b), this profile crosses the Saxothuringicum/Moldanubicum contact zone in the immediate vicinity of the KTB drilling site, and enters geological units largely equivalent with those of our profile 2 . In this area the two profiles run close to each other, at a distance of about 15 to $30 \mathrm{~km}$ only.

Even that about $200 \mathrm{~km}$ apart, the above investigations on the German territory indicate similar large-scale geoelectrical features attributed evidently to the Variscean structural zoning. First, a continuous conductive layer is interpreted within the depth range of 8 to $13 \mathrm{~km}$ in the crust of both the regions studied, with a peak conductance of as much as $10000 \mathrm{~S}$ immediately beneath the Mid German Crystalline High. Towards the south, the conductance of this layer decreases rapidly, to make only about $500 \mathrm{~S}$ near the Saxothuringicum/Moldanubicum transition (Hofer, 1990). Tauber (1993) gives an estimate of $100 \mathrm{~S}$ near the KTB site. According to the induction arrows, the strike of this crustal conductor is clearly Variscean (Hofer, 1990), i.e. NESW, to the east of the Rhine Graben. Along the eastern profile, with the geomagnetic induction data indicating an almost pure E-W strike of the crustal conductive layer (Eisel, 1990; Tauber, 1993), this pattern seems to be distorted. Large anisotropy of the MT impedances, which is the second common feature of both data sets involved, displays a similar directional inconsistency. While along the western profile the minor impedances are mostly parallel to the Variscean trend and the major impedances correlate well with the undulations of the crystalline basement (Hofer, 1990), the MT anisotropy particularly in the Oberpfalz area shows just a reversed character, with the direction of preferred conductivity being NW-SE (Eisel, 1990; Tauber, 1993). To account for this anomalous behaviour of the MT data, high macro-anisotropy of the electrical conductivity within the earth's crust of the area was proposed, and for the immediate vicinity of the KTB drilling site also evidenced by geological results (Eisel, 1995).

The specific objective of the geoelectrical studies along the profile 2 in West Bohemia was, on the one hand, to correlate the large-scale geoelectrical features within the area between the immediate KTB region in the west and the West Bohemian fault zone in the east, i.e. substantially within the same regional geological environ, and, on the other hand, to detect deep-seated changes in the geoelectrical structure when passing into the different geological conditions of the TepláBarrandian Proterozoic unit in the east. To accomplish the latter goal, the experiments described earlier were further supplemented with several test soundings, arranged along two short profiles (profiles 2a and 2b in Fig. 1, called 'Tachov region' and 'Kdyně region', after the nearby towns), which cross the West Bohemian faults and try to approach the corresponding stations on the regional profile 1 . In what follows we will discuss the character of the data obtained in the region of interest, and present some analyses and modelling results relating to the problems formulated above. 


\section{Geomagnetic Transfer Functions and Magnetotelluric Data}

\subsection{Geomagnetic transfer functions}

Long-period geomagnetic transfer functions and induction arrows are excellent characteristics to assess the large-scale induction features and induction anomalies within the region under study. A preliminary estimation of the induction effect of the structure involved was based on the analysis of geomagnetic transfer functions for long periods, typically in the period range of 10 to about 120 minutes, within the array of 10 stations indicated as 'MV' in Fig. 1. The data were already analyzed in (Červ et al., 1993) in detail. The main conclusions based on the behaviour of both the single station and reference station geomagnetic transfer functions (with the observatory Budkov in South Bohemia as the common reference station, Fig. 1) can be summarized as follows:

(i) The single station transfer functions fit well the general over-regional pattern with the predominant orientation of the real induction arrows towards the $S$ and decreasing moduli towards the $\mathrm{E}$ or SE. Single station induction characteristics reflect rather regional structural features characterized by a predominant E-W strike.

(ii) Reference station real vectors, defined here via relating the difference of the local and reference vertical magnetic field to the linear combination of the horizontal components of the reference field in the frequency domain, are systematically rotated by 30 to 40 degrees towards the $\mathrm{SE}$ compared to the single station vector orientation. Reference station induction characteristics are formed by local geological features. Their dominating strike is SW-NE which conforms with the main tectonic features of the region, in particular with the contact zone of the Saxothuringian and Moldanubian tectonoblocks, identified with the Litoměr̆ice fault zone striking SW-NE-ward.

From the MT data collected along the profile 2, only single station transfer functions were evaluated. In Fig. 2 we present the induction arrows, both the real and imaginary, for our profile along with the real induction arrows from two other profiles from the region of interest. The first data set (Fig. 2a), from a region more to the W, was presented by Tauber (1993) for a N-S profile passing immediately the KTB area and running close to the Franconian Line in the Saxothuringian and Moldanubian blocks. The other set (Fig. 2d) was obtained along the northern and central part of the profile 1 (Klause et al., 1994).

Along the profile 2 , the real induction arrows are generally rather large, with the moduli as much as 0.3 in the $\mathrm{N}$ of the profile, and directed almost uniformly to the $\mathrm{S}$ (Fig. $2 \mathrm{~b}$ ). A slight deviation, within 10 degrees at the most, to the $\mathrm{E}$ is observed near the northern end of the profile. Approaching the southern section of the profile, notably starting from the station $\mathrm{NOHU}$, a deflection of the induction vectors by more than 20 degrees towards the $\mathrm{W}$ takes place. Induction response, measured by the moduli of the real induction vectors, seems to decrease gradually from the $\mathrm{N}$ to the $\mathrm{S}$, where the lengths of the real vectors do not exceed 0.15 .

Imaginary transfer functions (Fig. 2c) are very small as compared with the real ones, and their azimuths are largely scattered due to the noise effect. In an apparently chaotic distribution of the imaginary vectors, certain regularity seems to persist anyway, consisting in the existence of a zone of antiparallel orientation, in relation to the real vectors, within the range of periods of about a few tens of seconds to approximately $1000 \mathrm{~s}$.

When compared with other results of the GDS in the region involved, the induction arrows along the profile 2 exhibit a striking similarity with those presented by Tauber (Fig. 2a). Unfortunately, Tauber's profile ends too early in the south to confirm the westward deviation of the induction arrows described earlier for the southern section of our profile.

The geomagnetic induction data from the profile 1 indicate a much more complex pattern of geoelectrical changes along that traverse. Contrary to the uniform induction pattern along the profile 2, the arrows along the profile 1 indicate a strong influence of numerous local distorters, and fit into the over-regional pattern only at long periods, specifically greater than $300 \mathrm{~s}$. The westward deviation of the arrows in the central and southern section of this profile is expressed 


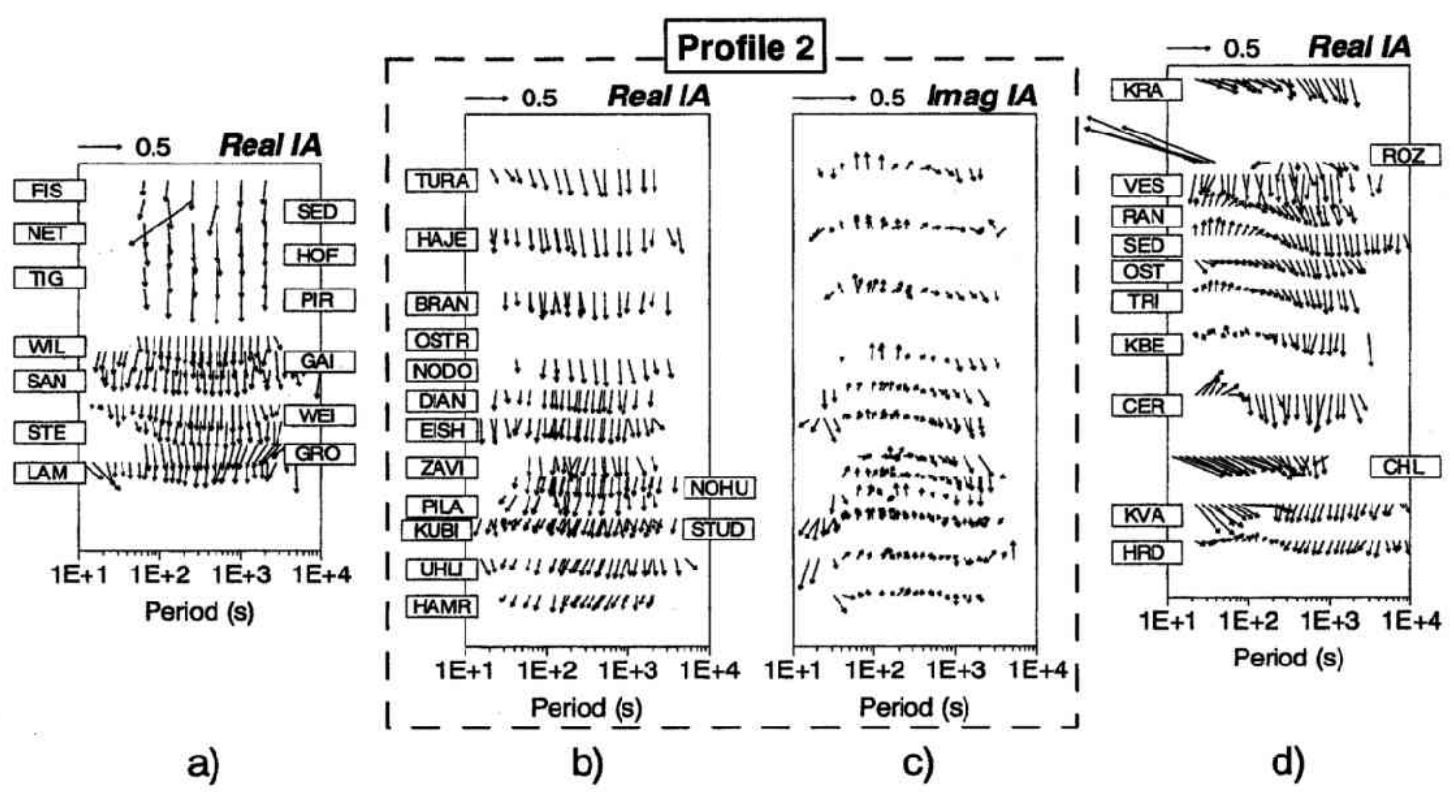

Fig. 2. Induction arrows along selected profiles in the western part of the Bohemian Massif for comparable latitudes and for the period range 10-3000 s. a) Real induction arrows along the profile of Tauber (1993). b) Real and c) imaginary single station induction arrows along the MT profile 2 in SW Bohemia. d) Real induction arrows along the northern and central part of the profile 1 in W Bohemia (Klause et al., 1994).

clearly, and, similarly as for the profile 2, seems to be related to a zone along the Central Bohemian deep fault (suture).

Along the northern section of the profile 1, the real arrows have an appreciable east component, which conforms much better with the generally almost SW-NE strike of the large-scale regional tectonic boundaries. The same is observed for the data from the west of the Franconian Line as well (Hofer, 1990). In this respect, the almost pure southern orientation of the real arrows along Tauber's and our profile, both within the Moldanubian protrusion in between the Franconian Line and the West Bohemian fault zone, might indicate a large-scale distortion of the geomagnetic induction data within that specific zone.

\subsection{Magnetotelluric data and magnetotelluric parameters}

Magnetotelluric data are in general more informative, especially with regard to the vertical resolution of the conductivity distribution, but they are highly sensitive to various distortions, in particular to the cultural noise, which corrupts the raw time series, as well as to the geological noise, which can result in uncontrollable shifts of the resistivity curves.

The MT data along our profile 2, represented in Fig. 3 by means of the modified polar diagrams, display a rather 3-D character, with the principal axes varying in both the size and direction along the profile. Even in the principal directions, the secondary impedances are still relatively large, and cannot be considered negligible. There is an evident discrepancy between the principal directions of the impedance tensors and the azimuths of the induction arrows.

For any of the stations, Swift's principle direction is stable, within a few degrees, throughout the whole period range from 10 to about $1000 \mathrm{~s}$. It varies, however, non-systematically, from station to station, although the major axes of the polar impedance diagrams are mostly found 


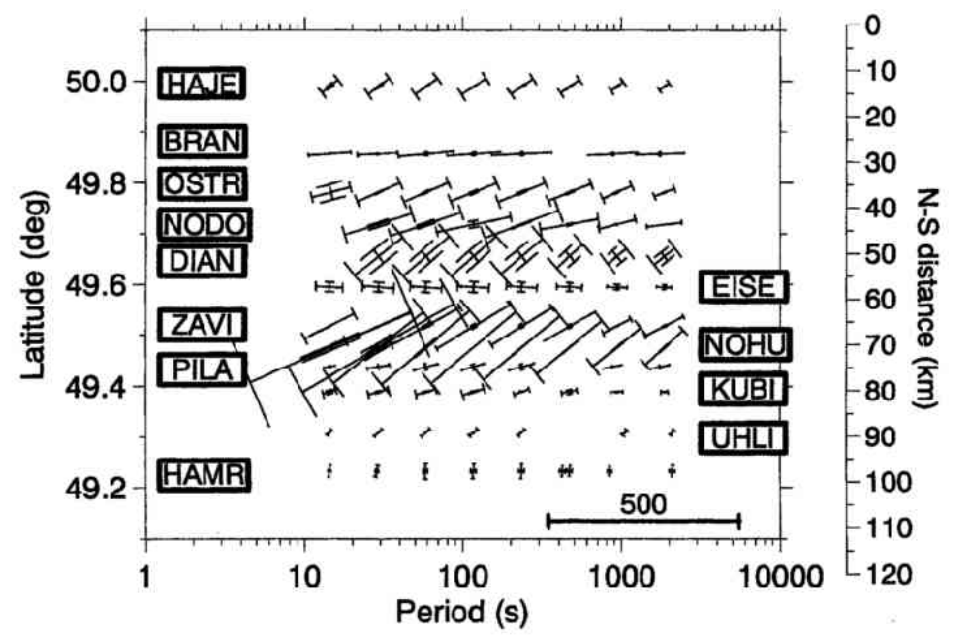

Fig. 3. Modified polar impedance diagrams at the stations along the profile 2 for a set of periods. The moduli of the minimum and maximum impedances are represented by lines of proportional length oriented in the respective Swift's principal direction. At the end of the $\left|Z_{\max }\right|=\left|Z_{x y}^{\mathrm{rot}}\right|$ and $\left|Z_{\min }\right|=\left|Z_{y x}^{\text {rot }}\right|$, the corresponding secondary impedances, i.e. $\left|Z_{x x}^{\text {rot }}\right|$ and $\left|Z_{y y}^{\text {rot }}\right|$, respectively, are shown, in the same scale, by perpendicular bars. To avoid scaling difficulties, the impedances are multiplied by the square root of the period. The scale bar corresponds to $500(\mathrm{mV} / \mathrm{km} \mathrm{nT}) \mathrm{s}^{1 / 2}$. Two sites from the profile are not shown here-TURA could not be evaluated due to excessive telluric noise, and at STUD the digrams are extremely small as compared to other sites.

within the octant from 45 to 90 degrees.

The MT anisotropy, defined by the ratio of the moduli of the major and minor impedance in the Swift's principal direction, is another parameter stable with period but variable from station to station. The anisotropy is generally large at most of the stations involved, typically around 10 , reaching its maximum about $10^{2}$ at the station NOHU.

Another classical MT parameter, skew, defined as a ratio $\kappa=\left|Z_{x x}+Z_{y y}\right| /\left|Z_{x y}-Z_{y x}\right|$, varies also rather randomly along the profile. In Fig. 4, skew is shown as a 3-D plot along the profile (more exactly, along the N-S projection of the profile, which reflects better the hypothesized E-W regional strike) and compared with the MT error parameter, $\varepsilon=\sqrt{\delta Z_{x y}^{2}+\delta Z_{y x}^{2}} /\left|Z_{x y}-Z_{y x}\right|$, (Bahr, 1991). We can see that, at most of the stations, the skew is too large to allow a 1-D approximation of the structure to be accepted. It reaches its minimum at BRAN, which seems to be the only station where the condition of zero skew, and consequently of minimum (or apparently minimum) effect of 3-D distortions can be reasonably accepted.

To summarize, the principal features of the MT data seem to contradict the simple conclusion on the E-W strike of the structure, derived earlier from the induction arrows. MT polar impedance diagrams would rather indicate SE-NW or SSE-NNW as a direction of the preferred conductivity for the structure. This pattern is characteristic not only for the data from SW Bohemia, but seems to be of more regional extent, as indicated in (Eisel, 1995) and (Tauber, 1993) by the MT data from the Oberpfalz, Germany. In principle, three possible sources of this discrepancy, or more likely a combined effect of some of them, may be considered - a substantially 3-D character of the structure, galvanic distortions of the MT data, and physical macro-anisotropy of the electrical conductivity within the structure on a regional scale. 


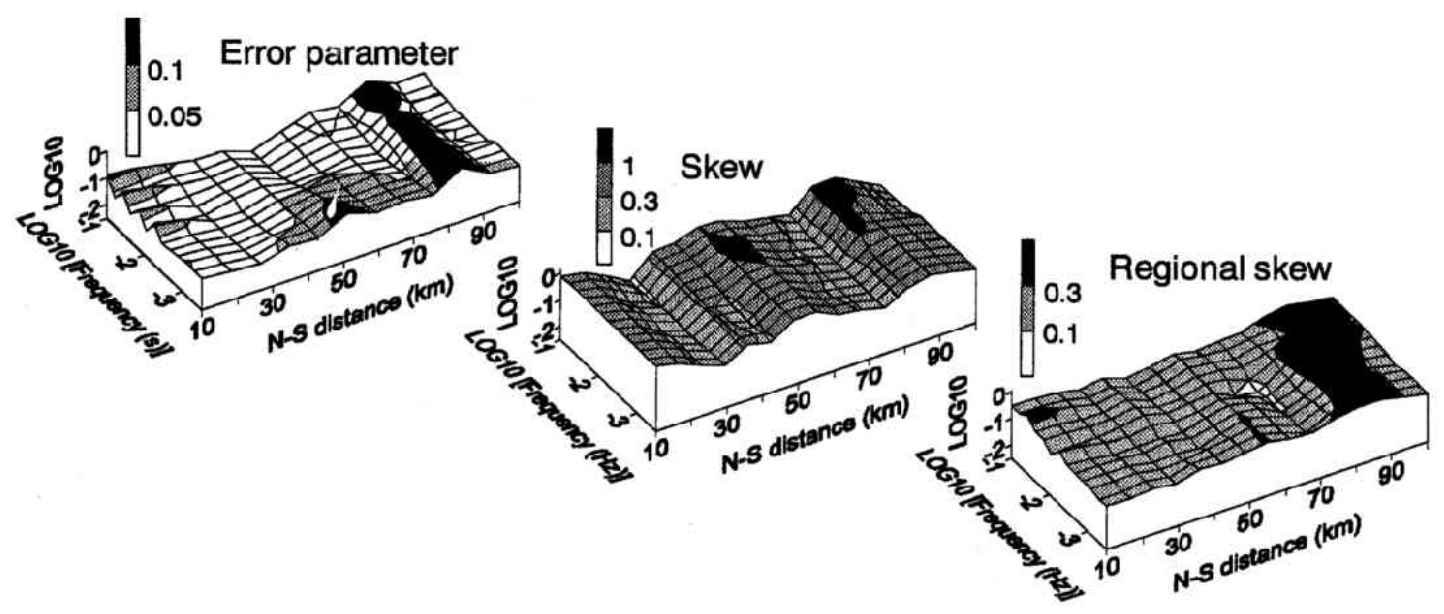

Fig. 4. Error parameter, classical skew and phase sensitive regional skew (1) along the profile 2 as a function of the period.

\section{Distortions of the Magnetotelluric Data}

\subsection{Distortion indicators and decomposition attempts}

The idea of rather strong galvanic distortions of the MT data by near-surface heterogeneities along the whole profile seems to be supported by rather random fluctuations of all the classical MT parameters over distances of a few kilometers only, which certainly does not indicate that the deep structure varies so dramatically across so short distances. Taking into account the typically high resistivities in the area, often more than $10^{3} \Omega \mathrm{m}$, we must emphasize, however, that the 'near-surface' character of the distorting structures may in fact represent a distorting effect of a layer several kilometers thick here, if periods greater than $10 \mathrm{~s}$ are considered.

Visual inspection of the MT curves can give a qualitative idea as to the character of the distortions. For the major part of the profile, particularly northernward of KUBI, the sounding curves show similar features, illustrated here by the unrotated curves from the station OSTR (Fig. 5). In the MT period range, one pair of the impedance components, specifically $Z_{x x}$ and $Z_{y x}$, dominates the impedance tensor. The phases within the individual columns of the impedance tensor are close to each other, at least for longer periods above $100 \mathrm{~s}$. The latter feature is almost perfectly expressed for the dominating impedance pair, whereas it is less convincing, and, due to greater errors, partly hidden for the other pair of impedances, i.e. $Z_{x y}$ and $Z_{y y}$. Physically, those impedance relations suggest the dominant role of $H_{x}$, i.e. the northern component of the geomagnetic variation field, in the induction process. The electric field is controlled mainly by a single magnetic component, and the telluric components $E_{x}$ and $E_{y}$ are highly correlated. In terms of the static distortions, the above impedance relations would indicate a 2-D regional structure, striking nearly E-W or N-S , and an additional galvanic distortion described by a static tensor with one dominating column, resulting physically in a pronounced linear polarization of the telluric field. In Fig. 6 we further demonstrate the consistency of the above general features of the MT curves along the whole northern and central section of the profile by showing the apparent resistivities and phases simultaneously for a subset of stations.

Additional support to the hypothesis of the large static distortions of the MT data is given 

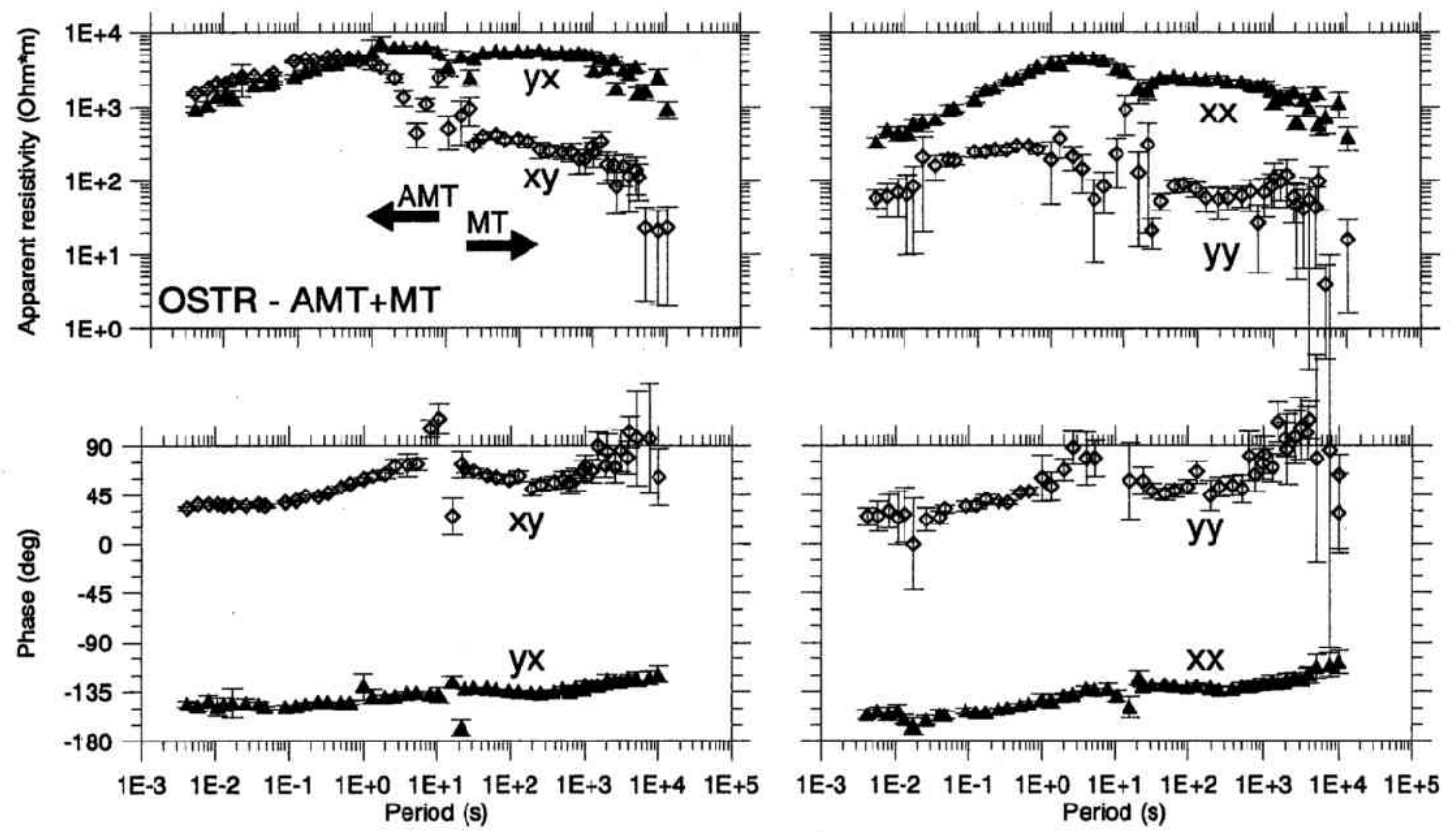

Fig. 5. Complete set of the AMT and MT apparent resistivities and phases at the station OSTR, in N(x)-E(y) coordinates.
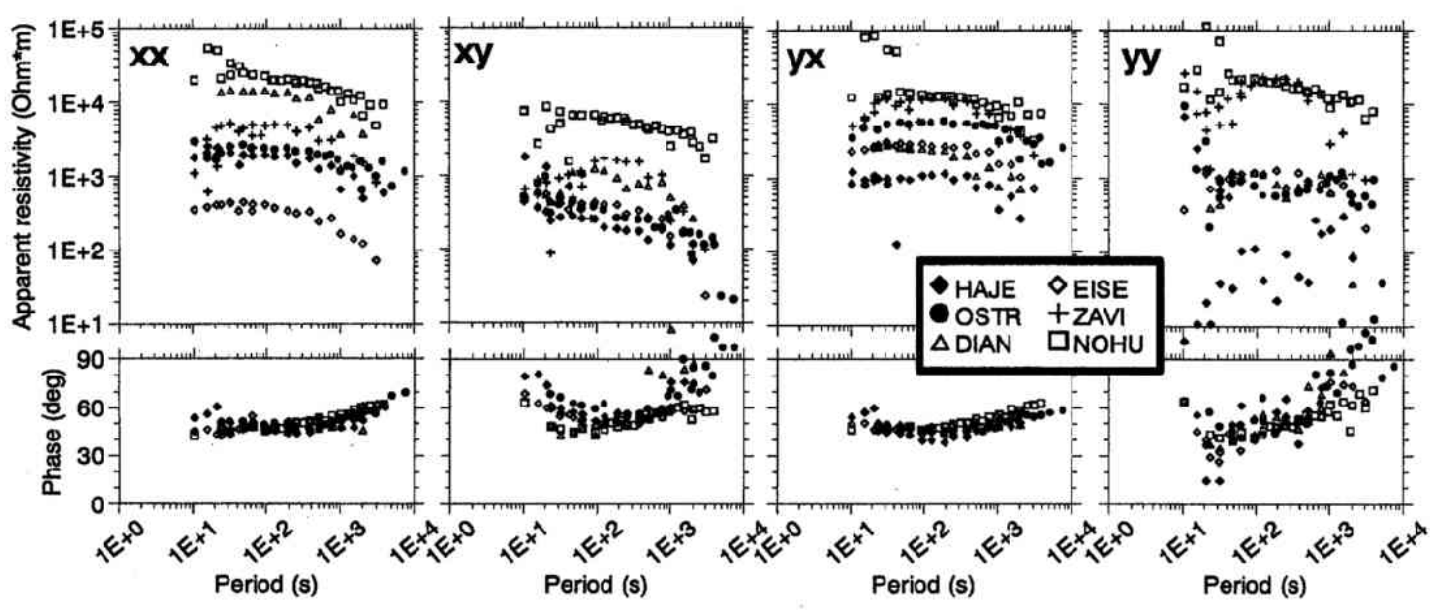

Fig. 6. MT resistivity and phase curves, in $\mathrm{N}(x)$-E(y) coordinates, for a subset of stations from the northern and central part of the profile 2. Phases are transformed to be within the interval $\left(0^{\circ}, 90^{\circ}\right)$. The error bars are omitted. 
by the inspection of the phase sensitive regional skew $\eta$ (Bahr, 1991) along the profile (Fig. 4),

$$
\eta=\frac{\sqrt{\left|\Im\left(Z_{y x} Z_{x x}^{*}-Z_{x y} Z_{y y}^{*}\right)\right|}}{\left|Z_{x y}-Z_{y x}\right|} .
$$

Except in the anomalous zone near the southern end of the profile, this parameter is mostly less than 0.3, which, according to (Bahr, 1990), may indicate that a substantial part of the 3-D effects originates in the near-surface inhomogeneous structures.

Attempts to verify the above scheme quantitativelly, and to carry out an exact separation of the local and regional contributions to the impedances, were successful only partially with our MT curves, as data of exceptionally high quality are required for the current decomposition techniques to provide statistically significant conclusions (e.g. Bahr, 1990; Jones and Groom, 1993). Often the conclusions can be only hypothesized from the conformity of the estimated decomposition parameters across a certain period range and across a certain region, rather than based on a statistically significant set of independent single-period and single-site results.

In Fig. 7 we present some results of the decomposition analysis for the station OSTR, where relatively high quality data were recorded. Figure $7 \mathrm{a}$ shows the basic MT parameters for that

a)

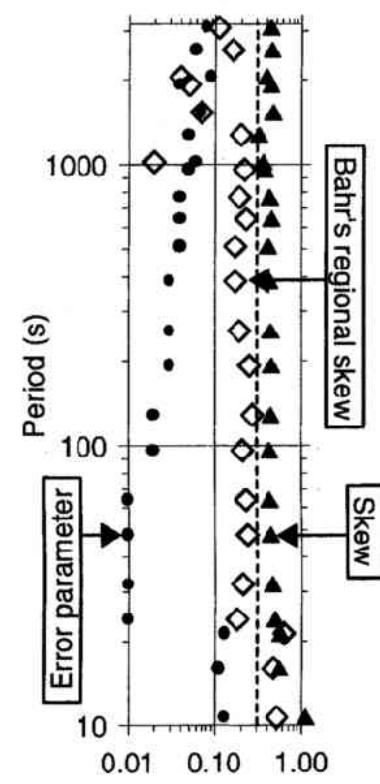

b)

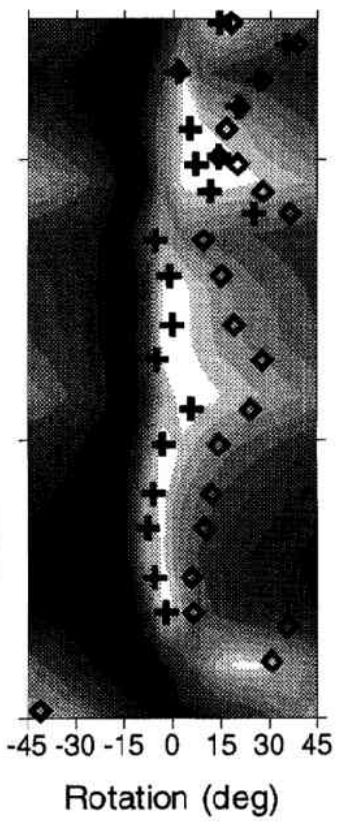

c)

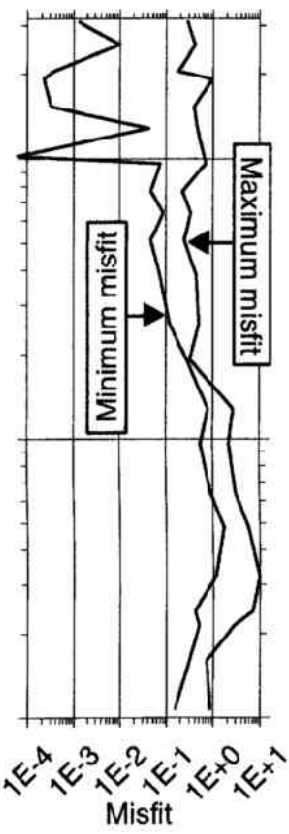

d)

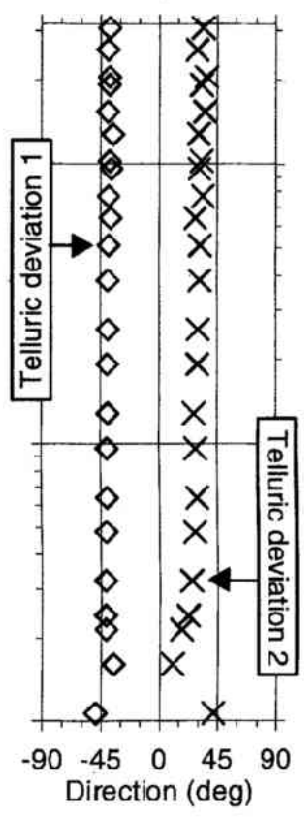

Fig. 7. MT decomposition parameters for the data from the site OSTR. a)-Error parameter (dots), classical skew (triangles), and Bahr's regional skew (diamonds). The conventional limit 0.3 for the Bahr's $\delta$-model is shown by the dashed line. b) -Bahr's regional strike (diamonds) and the regional strike derived from the $\delta$-model (crosses), shown for periods with $\delta<5^{\circ}$. The gray-scale plot displays the misfit of the model impedances, obtained from Groom and Bailey's decomposition model, to the experimental data as a function of the regional strike direction, in a homogenized scale from 0 (white) to 1 (black). c)-The maximum and minimum misfit of the Groom-Bailey decomposition model for all directions as a function of the period. d)--The telluric deviations, $\beta_{1}$ and $\beta_{2}$, as a function of the period, for the mean value of the regional strike, $\bar{\alpha}_{\mathrm{REG}}=3.2^{\circ}$ (all data with $\delta<5^{\circ}$ used to compute the mean, without considering the error parameter). 
site - the error parameter, the classical skew, and Bahr's regional skew-as a function of the period. With regard to the error parameter, the regional skew cannot be considered negligible, i.e. a certain part of the distortions of the MT data must be attributed to the induction effects in the non-homogeneous deep regional structure. Nevertheless, Bahr's skew is relatively small, less than 0.3 practically all over the period range involved, which is the upper limit Bahr suggests for his generalized composite $\delta$-model (i.e. 3-D local structure and a moderately distorted 2-D regional structure) to be applicable to the structure analyzed, provided that $\delta$, representing the difference of phases in the individual columns of the impedance matrix rotated into the regional strike, can be kept reasonably small (Bahr, 1990).

Figure $7 \mathrm{~b}$ shows the estimates of the regional strike for the individual periods obtained by the use of Bahr's basic model (3-D local/2-D regional structure, regional skew considered zero, shown by diamonds) on the one hand, and by the generalized $\delta$-model (crosses) on the other. In the background, a gray-scale plot illustrates the results obtained by the analysis according to Groom and Bailey (1989). Specifically, the plot shows the misfit between the model impedances, parametrized according to Groom and Bailey (1989), and the experimental impedances, each time for a fixed regional strike, which is changed in subsequent runs so as to scan the whole quadrant $\left(-45^{\circ},+45^{\circ}\right)$. As the range of the misfits can vary largely for different periods (see Fig. $7 \mathrm{c}$ ), we project, at each individual period, the whole range of misfits (or, here, their logarithms) for various strikes onto the interval $(0,1)$, to homogenize the scale.

By comparing the decomposition results, we find that a relatively stable estimate of the regional strike is obtained both from Bahr's $\delta$-model and the Groom-Bailey decomposition. The estimated regional strike is close, within a few degrees, to the principal geographical directions, which would support the pattern derived earlier from the real induction arrows, i.e. the existence of an almost E-W striking deep regional structure, covered by a distorting layer.

The character of the local distortions can be assessed by analyzing other decomposition parameters. In Fig. $7 \mathrm{~d}$ the telluric deviations, or 'skew angles' (Bahr, 1990), $\beta_{1}$ and $\beta_{2}$, are shown for a mean value of the regional strike estimate across the whole period range. These parameters are related to the shear and twist parameters of Groom and Bailey (1989) via simple formulae, shear $=\left(\beta_{1}+\beta_{2}\right) / 2$ and twist $=\left(\beta_{1}-\beta_{2}\right) / 2$. Similarly as the regional strike estimate, the telluric deviations are also sufficiently stable within the period range studied, with relatively large mean values, $\bar{\beta}_{1} \approx-35.1^{\circ}$ and $\bar{\beta}_{2} \approx 29.6^{\circ}$, which indicates rather large distortions of the telluric field at the locality investigated. A more detailed analysis of the MT data from the particular locality OSTR in Červ et al. (1993) showed further that a stable apparent local strike can be derived from the data, close to the azimuths of the real reference station induction arrows mentioned earlier. Different estimates of the apparent local strike are concentrated within the range of 40 to 50 degrees, and, although we cannot attribute them to any particular tectonic feature, they conform well with the roughly SE-NW and SW-NE strikes of the regional geology.

In Fig. 8 the estimates of the regional strike, based on Bahr's $\delta$-decomposition, are shown for other stations from the northern and central part of our profile. At some stations, the scatter of the values is rather large (e.g. ZAVI), and the data quality is evidently insufficient for the decomposition analysis to give any indications with regard to the composite model. Most of the sites show, however, a consistent picture of the regional strike estimates which are close to $0^{\circ}$ in the northernmost section of the profile (top row of plots in Fig. 8), and display a slight tendency to rotate, within about $20^{\circ}$, to negative values for the southern stations (bottom row in Fig. 8). The latter feature may be of significance in connection with the systematic deflection of the real induction arrows in the southern section of the profile, described earlier. In (Klause et al., 1994), the increasing west component of the real induction arrows, observed near the transition of the Teplá-Barrandian zone into the Central Bohemian Pluton and the South Bohemia Moldanubicum, is hypothetically attributed to the increasing effect of a conductor situated further to the east of the profile 1. Similar effect can be, however, generated also by a conducting zone running parallel 


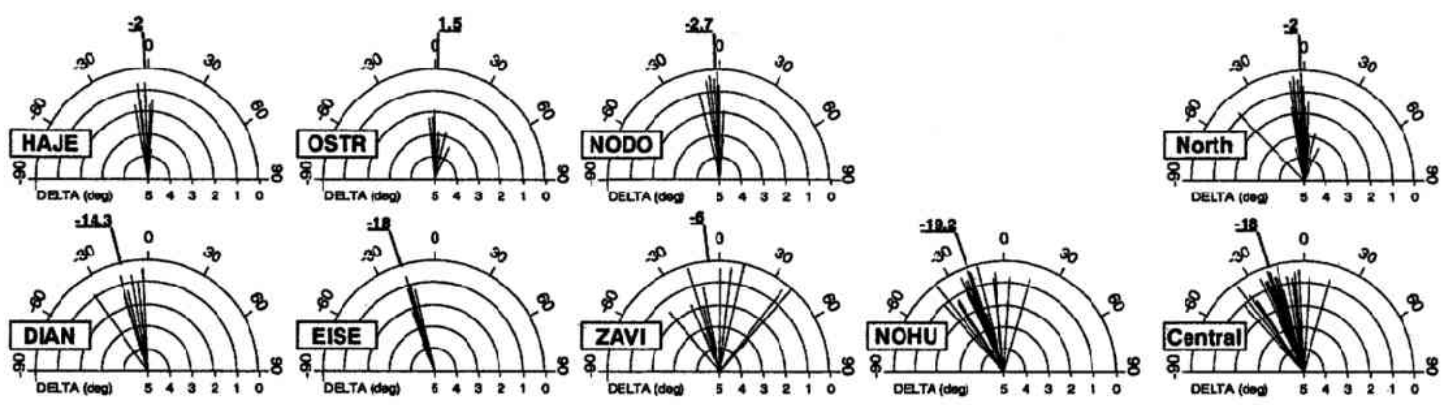

Fig. 8. Single-period estimates of the regional strike for the stations from the northern and central part of the profile 2. The direction of the rays shows the regional strike estimate for a particular period $\left(0^{\circ}\right.$ corresponds to $\mathrm{N})$, their length is proportional to $\left(5^{\circ}-\delta\right)$ for Bahr's $\delta$-model. The last column on the right-hand side summarizes all the estimates of the regional strike within the corresponding row of stations. Above each plot the arithmetic mean of the individual single-period estimates is given. Only data with $\delta \leq 5^{\circ}$ and with the error parameter $\varepsilon \leq 0.05$ were considered.

to the above contact zone of roughly SW-NE strike. Moreover, the inductive effect of such a zone could contribute to the observed systematic change of the estimated regional strike. Later we will evidence the existence of such a sharp resistivity drop along the Central Bohemian deep fault, within the space between the two principal profiles 1 and 2 at least.

\subsection{An experiment to estimate the absolute static shift of the MT impedances}

Even that the decomposition analysis provides us with valuable information with regard to the strike directions of both the regional and local structure, as well as the degree and character of the local distortions of the telluric field, the missing parameters of the absolute shift of the resistivity curves makes any interpretation rather difficult. Various approaches have been examined to fix the resistivity curves by exploiting independent information available, either from the shallow geoelectrical prospection, or from the geomagnetic deep variation studies, or from other structural considerations.

In (Červ et al., 1993) an attempt was made to estimate the absolute static shifts at the site OSTR by repeating Eisel's approach of fitting the long period branches of the local MT curves to Schmucker's continental GDS curve (Eisel, 1990). As neither Eisel's nor our curves contain reliable data in the period range of the harmonics of the daily variation of the geomagnetic field, Eisel used the nearby long-period station Hanfmühl, Germany, as a connecting link between his local MT data and the continental GDS curve. Though this approach, with the same intermediate link station Hanfmühl used (the distance to OSTR is about $20 \mathrm{~km}$ ), must be considered rather qualitative, we could obtain an estimate of the static shifts characterized by a largely eccentric telluric ellipse oriented approximately in the direction of the apparent local strike (major and minor semi-axes $A \approx 8.0$ and $B \approx 0.6$, respectively, eccentricity $A / B \approx 13.3$, direction of the major semi-axis $\alpha_{\mathrm{TEL}} \approx 54^{\circ}$ ). After deshifting the MT data, the anisotropy of the regional impedance almost disappeared.

For the other stations from the profile 2, we computed at first the inter-station MT transfer functions with respect to OSTR, $\mathbf{A}_{\mathrm{S}, \mathrm{OSTR}}(T)$, defined by

$$
\mathbf{Z}_{\mathrm{S}}(T)=\mathbf{A}_{\mathrm{S}, \operatorname{OSTR}}(T) \mathbf{Z}_{\mathrm{OSTR}}(T),
$$

where $\mathbf{Z}_{\mathrm{S}}$ and $\mathbf{Z}_{\mathrm{OSTR}}$ are the respective impedance tensors at the local station and at OSTR. If $\mathbf{A}_{\mathrm{S} \text {, Ostr }}$ is real and period independent in a certain period range, we can suppose that, within 
that range of periods, the two stations involved feel substantially the same regional structure, and differ from one another by the local distorting conditions only. Then, the absolute static shift at the local site can be estimated by combining the known estimate of the distortion matrix at the site OSTR with the corresponding inter-station transfer function, i.e.

$$
\mathbf{A}_{\mathrm{S}}=\mathbf{A}_{\mathrm{S}, \text { OStr }} \mathbf{A}_{\text {OStr }} \text {. }
$$

In Fig. 9, a typical example of the inter-station transfer function for the sites HAJE and OSTR is given. For periods greater than a few tens of seconds the components meet well both the above conditions - their imaginary part is close to zero, and they do not vary significantly with the period. A similar picture could be obtained for other sites as well, sometimes, however, the large error bars of the estimates reduce the statistical significance of the results substantially.

In Fig. 10a, the inter-station MT transfer functions with respect to OSTR are shown for all the stations along the profile in the form of relative telluric ellipses, which express how the telluric field at the individual station would be distorted if there were a circularly polarized field at OSTR. Combining the individual inter-station transfer functions with the estimate of the distortion matrix at OSTR, we could obtain rough estimates of the absolute distortion parameters at the individual stations. The corresponding absolute distortion ellipses are shown in Fig. 10b. They express how a normalized circularly polarized telluric field at infinity would be distorted by the local static shifts at the individual sites.

Similarly as at the site OSTR, also at the other stations the absolute telluric ellipses indicate extreme distortions of the telluric field throughout the region. A common typical feature is a large eccentricity of the ellipses, indicating large anisotropy of the conductance (either apparent or real) of the subsurface structures. The direction of preferred conductivity of the distorting layers, indicated by the minor axes of the telluric ellipses, is SE-NW to SSE-NNE at most of the stations. With regard to this general pattern, there is one distinguished zone of the anomalous behaviour of the distortion ellipses at the site BRAN in the northern section of the profile, with
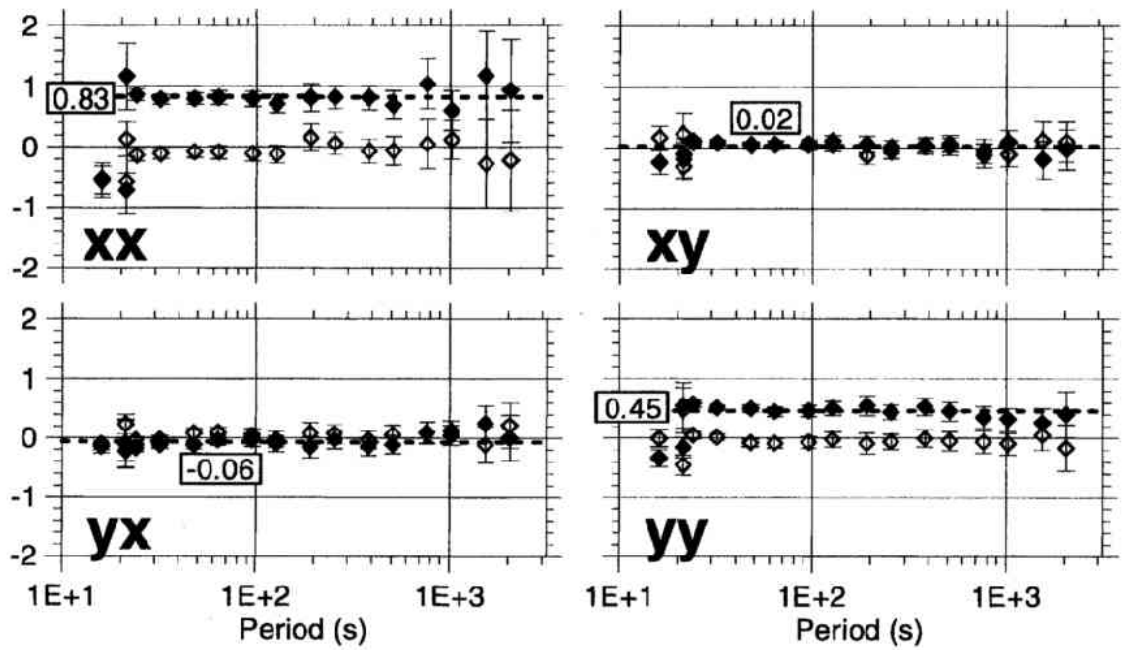

Fig. 9. Components of the inter-station MT transfer function for the site HAJE with respect to OSTR, as a function of the period. Full diamonds - real part, empty diamonds -imaginary part. In boxes, the mean values of the individual components across the whole period range are given. The vertical scales of the $x y$ and $y y$ plots are the same as those of the $x x$ and $y x$ plots, respectively. 


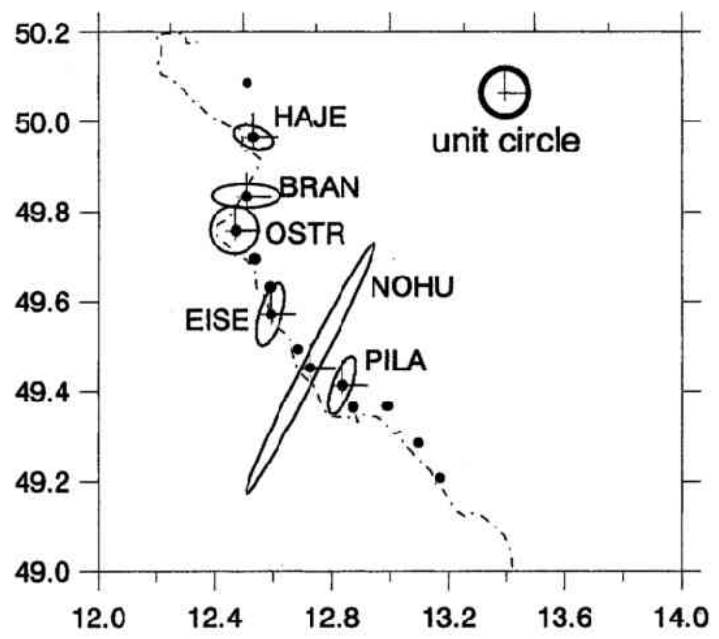

a)

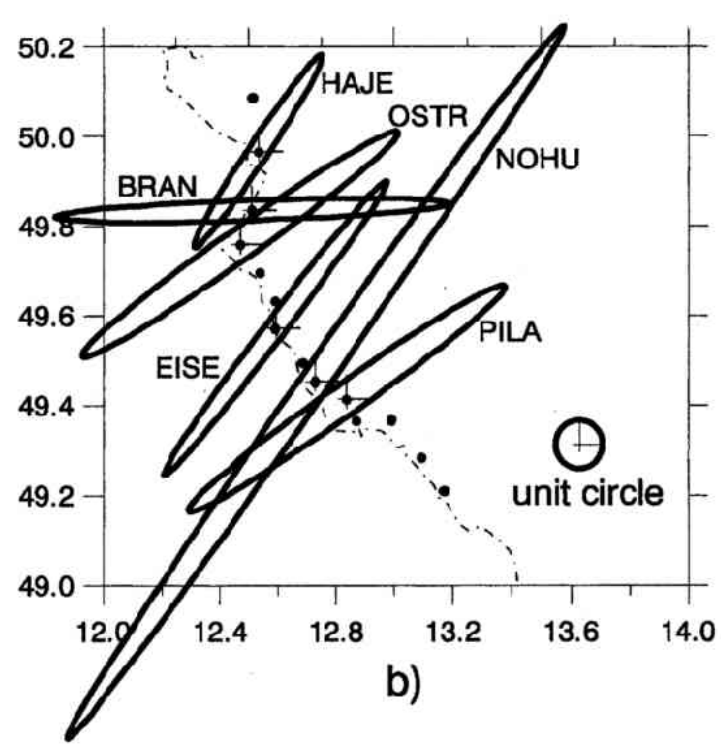

Fig. 10. a)-Relative telluric ellipses with respect to the site OSTR along the profile 2. b) -Estimates of the absolute distortion ellipses along the profile 2.

an enormously eccentric ellipse rotated almost exactly into the E-W geographical direction. The same picture is observed at the nearby site ZDAR on the profile $2 \mathrm{a}$, and seems to be connected with the influence of the high-resistive rocks of the nearby Bor Massif of the West Bohemian Pluton. Another site obviously distorted by additional large static effects is NOHU in the south of the central section of the profile. The southern section of the profile does not in general fit the quasi-homogeneous pattern of the impedances outlined above, and seems to be affected by more serious changes of the deep regional structure, taking place at the transition to the Sumava Moldanubicum.

The conclusions throughout this section give an idea with regard to the possible character of the composite model of the structure involved. It must be, however, emphasized that all the estimates presented above are of essentially qualitative character, as some highly approximate aspects are involved in the procedure. In particular, the following ones should be explicitely mentioned:

(i) Already the decomposition attempt at the site OSTR, presented in (Cerv et al., 1993), was carried out by a rather simplified approach of Eisel (1990) the long-period branches of the 'deskewed' curves from OSTR were fitted to the univariate 'deshifted', with respect to the continental GDS curve, impedances from the long-period station Hanfmühl, Germany.

(ii) The error bars of the estimates of the inter-station MT transfer functions are often too large to allow us to consider the results statistically significant, particularly for longer periods.

(iii) The variability of the inter-station MT transfer functions alone is often quite weak (e.g. less than 20 per cent along the displayed section of the model A in Fig. 12), and experimental data of extremely good quality are required to identify variations of the regional conductivity distribution. 


\section{Modelling Experiments}

\subsection{Formal 1-D modelling of roughly 'deshifted' $M T$ data}

To get a rough idea about the resistivities beneath the profile, we at first computed formal 1-D inversions of the MT curves, 'deshifted' by the distortion parameters estimated above. Specifically, 'deskewed' impedances $Z_{1}=\sqrt{\left(Z_{x x}^{2}+Z_{y x}^{2}\right)}$ and $Z_{2}=\sqrt{\left(Z_{x y}^{2}+Z_{y y}^{2}\right)}$ in the N-E coordinate system, which can be considered an acceptable approximation of the regional strike, were reduced by the corresponding shift factors $\bar{a}_{S 1}=\sqrt{\left(\bar{a}_{S x y}^{2}+\bar{a}_{S y y}^{2}\right)}$ and $\bar{a}_{S 2}=\sqrt{\left(\bar{a}_{S x x}^{2}+\bar{a}_{S y x}^{2}\right)}$, respectively, to provide roughly 'deshifted' regional impedances. At each site, the barred shift parameters were estimated as mean values of the elements of the local distortion matrix $\mathbf{A}_{S}$ over the long-period range. The imaginary parts of the distortion elements are generally small, and were neglected in the 'deshift' experiments. The error bars of the 'deshifted' MT curves were modified by the estimated errors of the inter-station distortion parameters. They are, however, of relative value only, as we have not been able to trace back the detailed error statistics and propagation throughout the whole cascade of steps of the 'deshift' procedure, especially as regards the fitting to the continental GDS resistivity curve.

For each site, the inversion was performed independently for the $E$ mode (i.e. E-W curve, according to the regional strike estimate which conforms both the MT data and induction arrows) and the $B$ mode (N-S curve). For the inversion, the controlled random search procedure (Martinez, 1988) was used, which allows noisy experimental data to be mapped onto a whole set of acceptable structural models. The typical size of the test model pool was 50 to 100 test models, the termination condition of the procedure was given either by the $\chi^{2}$-misfit criterion, or by the number of iterations, typically several tens of thousands. Both resistivity and phase curves were inverted simultaneously, and a slightly greater weight was put on the phases.

The results of the 1-D inversion for four selected sites are given in Fig. 11. Each section shows the best fit model, as well as the minimum and maximum envelope of the whole set of test models left in the test pool after the termination of the inversion procedure. Despite a relatively large range of the models' parameters allowed by the experimental MT data, some differences between both sets of models are recognisable, especially within the depth range of several $\mathrm{km}$ to about $20 \mathrm{~km}$, where the $E$-models (i.e. $y x$ ) systematically indicate a resistivity decrease, whereas the $B$-curves $(x y)$ allow for substantially higher resistivities throughout that range. At greater depths the models seem to merge in one common resistivity range.

Although the most substantial part of the anisotropy of the MT curves disappeared after we tried to roughly eliminate the static distortions, a systematic difference between the two modes persists in the models, indicating a virtually 2 -D character of the regional structure within the area under study, with apparently higher conductivity in the N-S direction.

\subsection{2-D modelling experiments}

Most of the modelling experiments presented below are based on the assumption that the structure may be decomposed into a 2-D regional substratum, striking E-W, and a generally 3-D near-surface distorting layer with only a static effect upon the MT data within the period range considered, i.e. for periods greater than a few tens of seconds. A lot of material presented in the preceding sections aimed at founding this hypothesis.

Considering such a structural outline, we assume that the observed induction arrows, as well as the phases of both the MT impedances, $Z_{y x}$ for the $E$-polarization and $Z_{x y}$ for the $B$ polarization, in the geographical coordinates, are undistorted functions of the regional structure, and can be used immediately to model the regional conductivity distribution.

The generally large and stable real induction arrows, directed approximately to the south, with gradually decreasing moduli from $\mathrm{N}$ to $\mathrm{S}$, can be explained by a variety of models. Common 

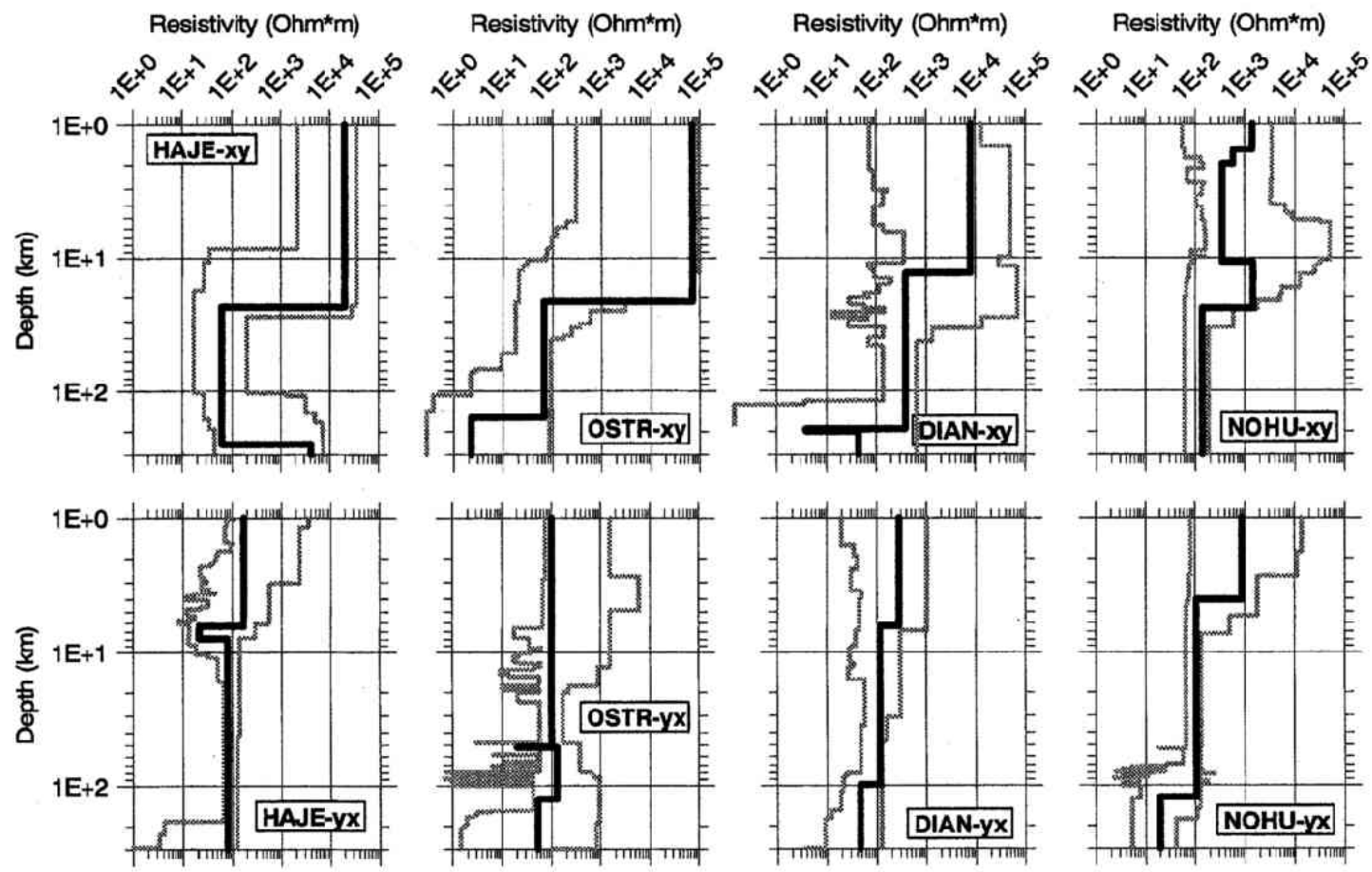

Fig. 11. 1-D formal inversions of the 'deshifted' MT curves at selected sites on the profile 2. The top row shows the results for the $E$-mode, i.e. E-W, curves, the bottom row for the $B$-mode, i.e. N-S, curves. Each plot shows the best fit model, obtained by the controlled random search procedure, as well as the minimum and maximum envelope of all the models left in the test pool after the inversion search has been terminated.

features of all of them are the E-W structural strike and a gradual decrease of the conductance towards the south. The MT phases at shorter periods put a constraint on the character of the models, in that they require a good conductor to be placed at upper crustal depths. In the model A in Fig. 12 a conducting thin layer was inserted into the structure, similar to that proposed by Eisel (1995) and Tauber (1993) for the Oberpfalz, Germany. By segmenting the layer into zones of different resistivities, the gradual decrease of the electrical conductivity towards the $S$, as well as local fluctuations of the data can be modelled. To simulate the principal source of the induction vectors, an extremely conducting segment was included into the layer at the northern margin of the model. Physically, this is in accord with the over-regional induction pattern, where the maximum moduli of the real induction arrows are observed above the Mid German Crystalline High, at the contact boundary between the Saxothuringian and Rhenohercynian units of the European orogen. The particular conductivities in the northern part of the layer, not covered by any measurements, are based on averaging the values used in several test models of Eisel (1990) and Tauber (1993), and further adjusted to provide the conductivity contrast necessary for generating the principal course of the induction arrows in the zone of our studies. In general, however, without any additional information available, there is large ambiguity of the electrical structure in the marginal parts of the model.

The parameters of the model A were determined by using the 2-D inversion procedure (Pek, $1987)$ to fit the experimental induction arrows and $E$-mode phases, the $H$-mode phases were only checked by the forward modelling. The inversion was repeated with the conducting thin layer 


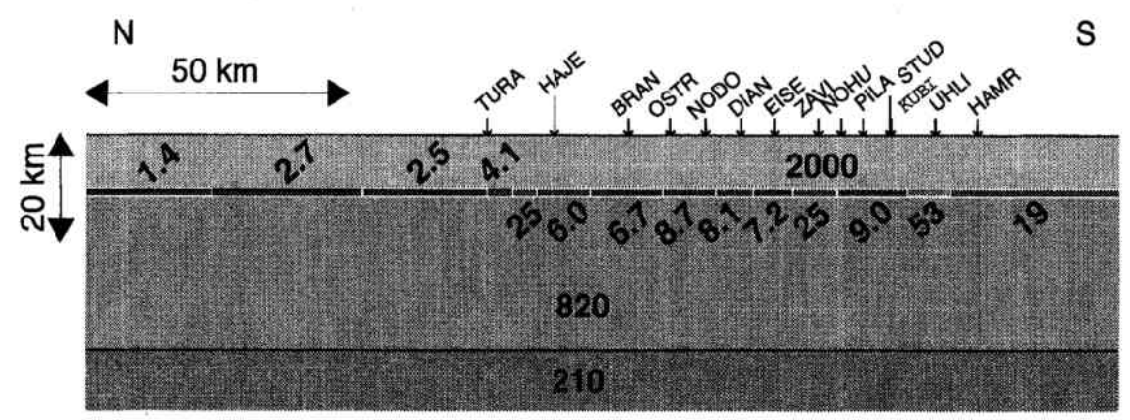

Fig. 12. Model A of the resistivity structure beneath the northern and central part of the profile 2. The segmented thin conductive layer is placed at the depth of $18.5 \mathrm{~km}$. The resistivities of the segments were determined by the 2-D inversion of the real induction arrows and $y x$-phases. The fit of the model data to the corresponding experimental functions is shown in Fig. 15. Numbers indicate resistivities in $\Omega \mathrm{m}$. Resistivity of the upper layer was chosen $2000 \Omega \mathrm{m}$.

placed at various depths, ranging from 10 to $25 \mathrm{~km}$. The particular model in Fig. 12, as well as the corresponding fit to the experimental data in Fig. 15, is shown for the depth of $18.5 \mathrm{~km}$. In all inversion runs, a very good fit of the real induction arrows was achieved, which only reflects the poor resolution of the geomagnetic induction data to the vertical conductivity features within the structure. For the phases, the model does not fit all the features of the experimental curves. In particular the large increase of $x y$-phases up to almost $90^{\circ}$ for short periods in the northern section of the profile could not be modelled with reasonable conductivities. With respect to the $B$-mode phases, models with the thin layer situated at greater depths would be preferable. This is rather different from the interpretation of the German data (Eisel, 1995; Tauber, 1993), where the best fit was obtained for the conducting layer at the depth of about $10.5 \mathrm{~km}$.

In Fig. 13 another inversion result is displayed, obtained by a different inversion technique, specifically by a version of the controlled random search (Martinez, 1988), adapted to cope with 2-D block models. Though the fit to the experimental data (Fig. 15) is worse as that for the previous model, mainly due to the extremely slow convergence of the inversion procedure, the main features of the data are still reflected by the results. The large differences of the resistivities

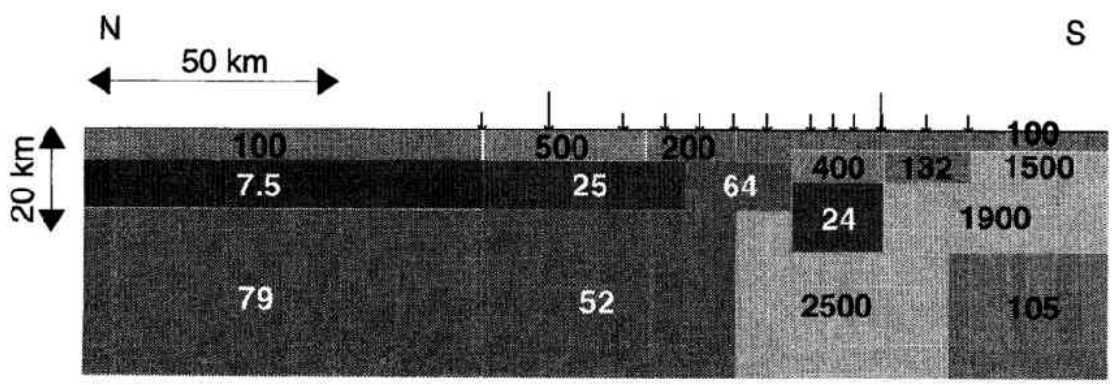

Fig. 13. Model B of the resistivity structure beneath the northern and central part of the profile 2 . The resistivities of the blocks were determined by the 2-D inversion of the real induction arrows, and both the $y x$ and $x y$-phases, by using the 2-D version of the controlled random search procedure. Only parameters for the best fit model are given. The fit of the model data to the corresponding experimental functions is shown in Fig. 15 . 
in the models A and B illustrate the ambiguity of the interpretation if no resistivity data are considered in the inversion. This refers particularly to the conductive layer, which extends over the range from about 7 to $15 \mathrm{~km}$ in the crust in the model B. If the roughly deshifted resistivities from the previous section were considered as a certain reference for the resistivity conditions, the model A would be preferable, especially with regard to the conditions in the upper crust.

The last model presented, model C (Fig. 14), tries to cope, at least qualitatively, with the discordance of the principal directions indicated by the induction arrows, on the one hand, and by the impedances on the other. The model extrapolates, in an extremely speculative fashion, Eisel's idea of a highly anisotropic block, striking approximately NW-SE and emerging immediately below the KTB site (Eisel, 1994, 1995). Eisel uses this anisotropic structure to explain his AMT and MT data from the immediate vicinity of the KTB borehole. Although this idea may be sound in the direct KTB area, and can be physically substantiated by the effect of steeply dipping structures of high resistivity rocks interspersed with highly conductive graphitized cataclastic zones, virtually observed both on the borehole log and on the surface in the KTB neighbourhood, it is rather speculative when extended to the regional scale. Nevertheless, there are indications of relevant common geological features of the KTB area and the Bohemian region to the west of the West Bohemian fault zone. In particular, Eisel (1995) presents a pattern of the late Variscan fracture zones in the KTB area, which came into existence during the late Variscan NE-SW compression and their generation was accompanied by the graphitization (cf. Behr, 1992). That NW-SE pattern covers almost uniformly the whole region involved, the area of the profile 2 included.

In model $\mathrm{C}$, the conducting thin layer was replaced by a highly anisotropic block in the upper crust, with the principal resistivities $30 / 10000 / 30 \Omega \mathrm{m}$ and with the anisotropy strike $\mathrm{N} 40^{\circ} \mathrm{W}$, to fit the above pattern. The structure was only forward modelled (Pek and Verner, 1997), as no inverse algorithm for the 2-D inversion with generally anisotropic blocks was available. Nevertheless, the model fits the induction arrows and MT phases almost equally well as the previous models (Fig. 15). Moreover, the extremely anisotropic layer excites highly anisotropic impedances along the profile, with anisotropy ratios $\varrho_{\max }^{a} / \varrho_{\min }^{a}$ typically close to 10 . Minor axes of the polar impedance diagrams are directed nearly exactly into the direction of the preferred conductivity of the anisotropic layer, whereas the orientation of the induction arrows is practically unaffected. The latter fact is due to a rather different behaviour of the induction arrows in structures with mutually interacting isotropic and anisotropic blocks, where the real arrows can be, under certain circumstances, oriented paradoxically into the direction of the preferred conductivity of the anisotropic block, and not perpendicularly to it, as one would expect (Pek and Verner, 1997).

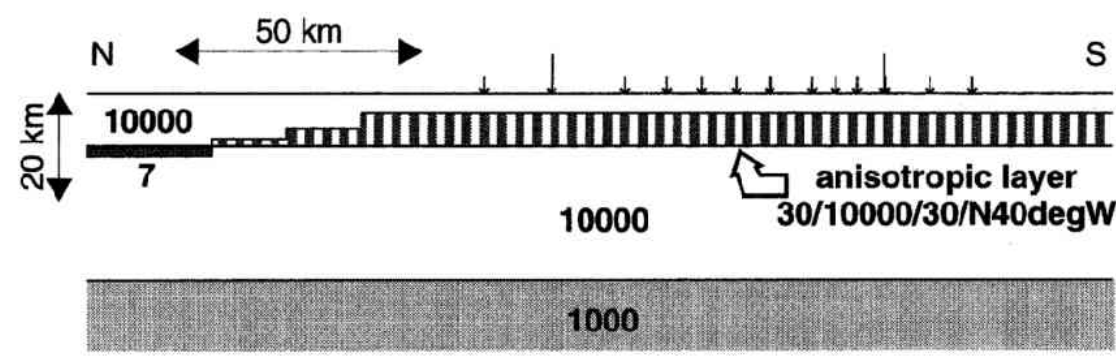

Fig. 14. Model $\mathrm{C}$ of the resistivity structure beneath the northern and central part of the profile 2 . The conductive layer is replaced by a highly anisotropic layer, with the principal resistivities $30 / 10000 / 30 \Omega \mathrm{m}$ and the anisotropy strike $\mathrm{N} 40^{\circ} \mathrm{W}$. The fit of the model data to the corresponding experimental functions is shown in Fig. 15. 


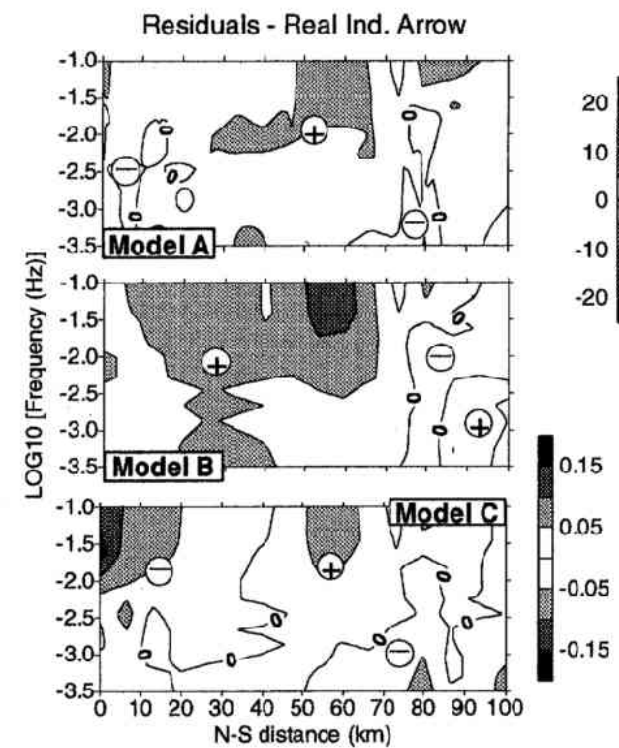

Residuals - Phase YX (deg)
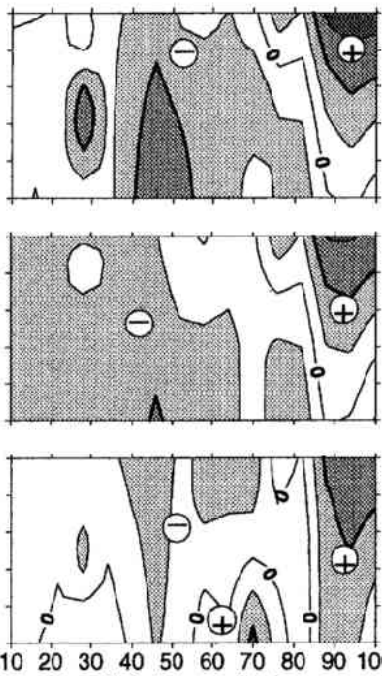

$\mathrm{N}-\mathrm{S}$ distance $(\mathrm{km})$
Residuals - Phase XY (deg)
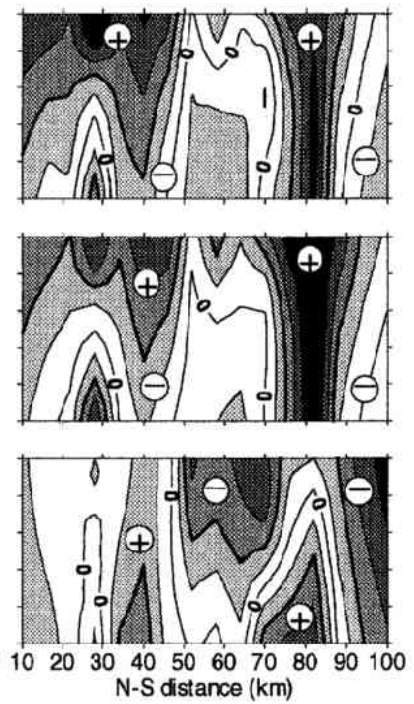

Fig. 15. Fit of the model results for the models $\mathrm{A}, \mathrm{B}$, and $\mathrm{C}$ to the experimental data in the form of the absolute values of residuals of the respective experimental functions from model responses. The residuals are non-weighted. The upper scale bar refers to the phase residuals, the lower one to the residuals of the induction arrows.

The anisotropic model $\mathrm{C}$ may be considered an equivalent model of a crustal macro-anisotropy, suitable in particular for the modelling purposes. It can explain the above general systematic difference of the principal directions of the GDS and MT data, it cannot, however, cope with the high spatial frequencies in the long-period MT impedances along the profile, which must be attributed to local telluric distortions. Another problem of the anisotropic model consists in relatively fast attenuation of the impedance anisotropy for long periods, which is in contrast with the practically constantly large anisotropies of the experimental resistivity curves. To produce the MT anisotropy as large as that indicated by the experimental impedances all over the period range involved, anisotropic blocks of unrealistically big size and $\varrho_{\max } / \varrho_{\min }$ ratio would have to be introduced into the model. In this respect, the local telluric distortions are likely to play the dominant role even in the large common NW-SE regional part of the MT anisotropy.

All the models have failed at fitting the highly anomalous behaviour of the MT phases in the southern section of the profile, with values close to $90^{\circ}$ in both $x y$ and $y x$ curves. In this region, however, all the MT parameters studied indicate rather exceptional conditions, with most likely significant 3-D effects involved.

\section{Magnetotelluric Measurements along Supplementary W-E Profiles}

\subsection{Main regional geoelectrical features along the profile 1}

To introduce the regional context of our supplementary MT experiments along the two short W-E profiles $2 \mathrm{a}$ and $2 \mathrm{~b}$ (Fig. 1), we briefly summarize the main geoelectrical results of regional significance from the broad-band profile 1 here, adopted from (Klause et al., 1994) and (Hudečková and Pícha, 1997). The profile 1 covers all the principal geological units of the West Bohemian region, from the Saxothuringicum in the north to the Teplá-Barrandian Proterozoic unit to the South Bohemia Moldanubicum in the south. It crosses the distinguished tectonic lines of the 


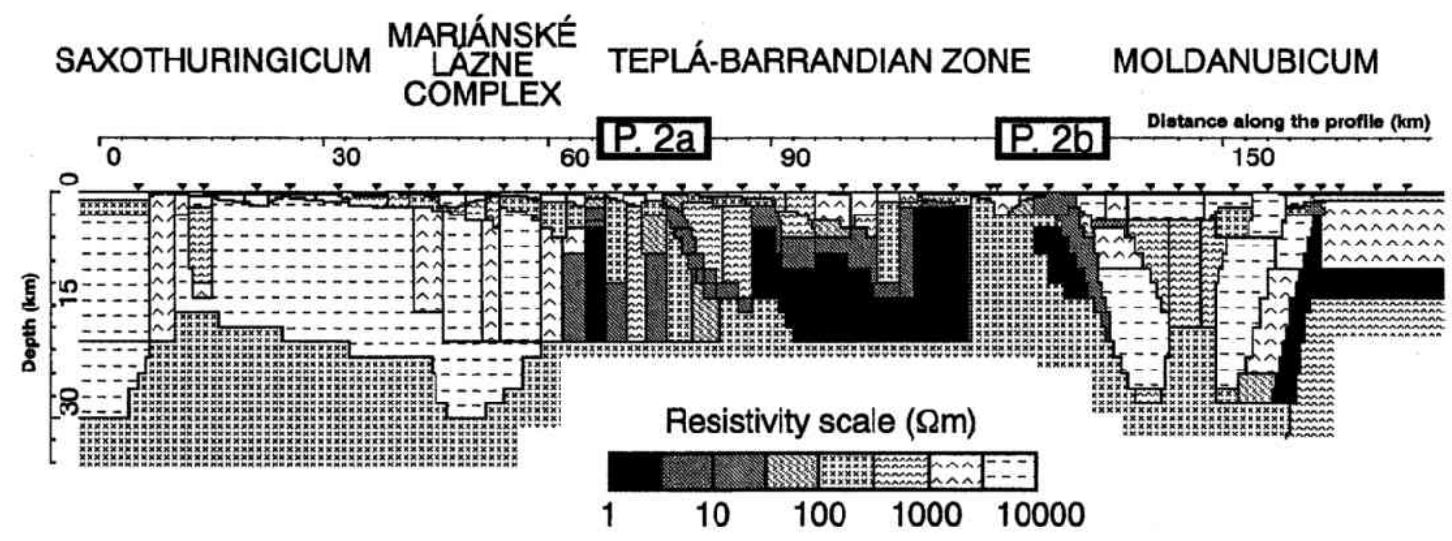

Fig. 16. 2-D model of the geoelectrical section beneath the broad-band regional profile 1 along the seismic reflection traverse 9HR in West Bohemia (Hudečková and Pícha, 1997). The model was optimized to fit the effective impedance (Berdichevsky invariant). The zones P.2a and P.2b indicate the regions where the local profiles $2 \mathrm{a}$ and $2 \mathrm{~b}$ approach the profile 1 from the west. The horizontal and vertical scales in $\mathrm{km}$.

area-the Litoměrice deep fault in the north and the Central Bohemian deep fault (suture) with the Central Bohemian Pluton at the contact between the Teplá-Barrandian unit and the South Bohemia Moldanubicum (see Fig. 1a for the geological reference).

In (Hudečková and Pícha, 1997) a detailed analysis of the data and their correlation with the seismic results along the geotraverse $9 \mathrm{HR}$, as well as with the regional geological modelling is given. The authors present a schematic geoelectrical cross-section beneath the profile, based mainly on the 1-D interpretation of the MT curves. A 2-D model, constructed from those interpretations and partly verified by fitting the effective apparent resistivities (Berdichevsky invariant), is shown in Fig. 16.

In this model, distinguished zones of different resistivities are indicated, correlated well with the geological differentation of the area involved. In the north, two pronounced high resistivity complexes - the Karlovy Vary Pluton and the Mariánské Láznë Complex (amphibolites)dominate the section all over the depth range shown. Further to the south, rather complex conditions of the Teplá-Barrandian Proterozoic unit (TBU) take place, with a uniformly lowresistivity base layer interpreted at variable depths, from 15 to $4 \mathrm{~km}$, all below that zone. The hypothesized coincidence of that resistivity boundary with the overthrust plane of the Moldanubian formations over the Saxothuringicum below could not be confirmed with the data resolution achieved. At the north of the TBU, in the merge zone of our profile $2 \mathrm{a}$ and the profile 1 (zone P.2a in Fig. 16), a pronounced geoelectrical anomaly indicates a recent hydro-geological structure in the area of the Konstatinovy Lázně spa.

Another marked anomaly is observed over the enlarged overthrust zone at the contact of the TBU with the Central Bohemian Pluton and the South Bohemia Moldanubicum, just beneath the section P.2b. This zone coincides with the Central Bohemian deep fault, and fits in with a segment of a global-tectonic deep zone, which traverses, in several discontinuous SW-NE segments, all the Bohemian Massif (Krs and Pruner, 1994).

\subsection{Magnetotelluric measurements along the sub-profile 2a, Tachov region}

The profile 2a (Fig. 17) consists of 4 long period MT stations arranged so as to cross the West Bohemian fault zone in the W-E direction and to merge with the corresponding stations on the regional profile 1 . The profile $2 \mathrm{a}$ represents a direct continuation of a detailed AMT profile 


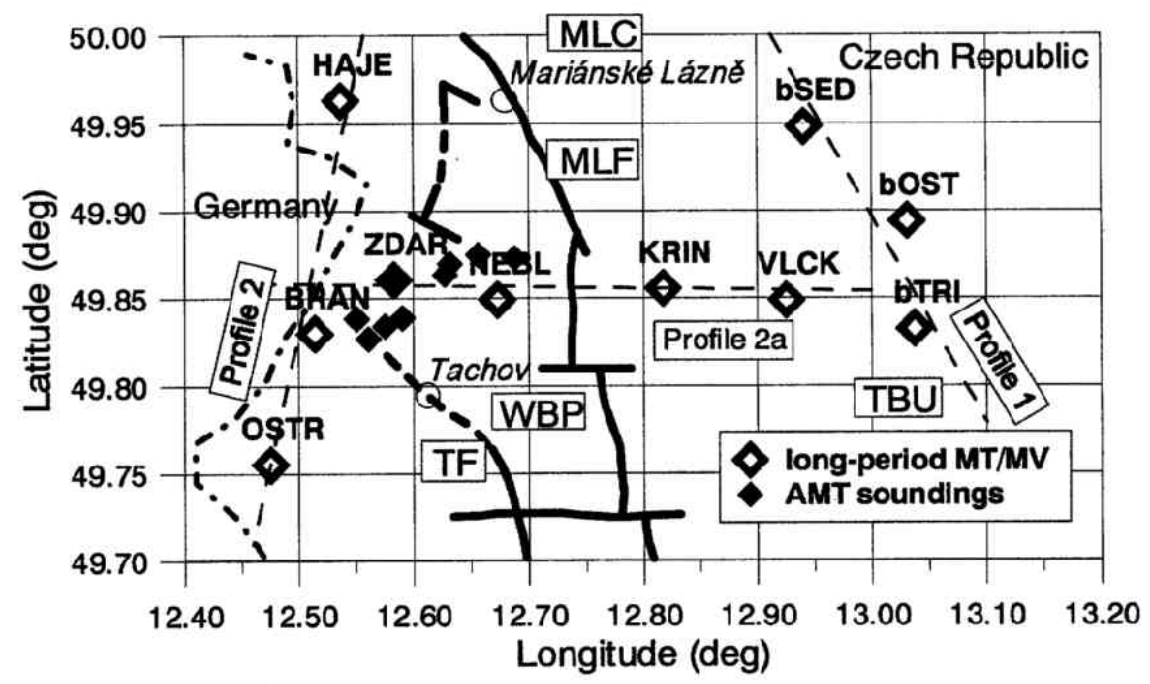

Fig. 17. Layout of the profile $2 \mathrm{a}$ and the nearby stations on the regional profiles 1 and 2 in the Tachov region. The geological units indicated in boxes are: TF-Tachov fault, MLF-Mariánské Lázně deep fault, WBP-West Bohemian Pluton, TBU-Teplá-Barrandian unit, MLC-Mariánské Lázně ultrabasic complex.

measured by the Italian staffs in the area north of Tachov earlier (Červ et al., 1997).

Geologically, the area of the profile $2 a$ represents a transition zone between, from $W$ to $E$, the Bohemian Forest Mts., the Bor Massif of the West Bohemian Pluton, and the Teplá-Barrandian unit. The region is marked by two significant fault zones- the Tachov fault, considered seismoactive, and the Mariánské Lázně fault. From the north, the body of the Mariánské Lázně ultrabasic complex extends into the area involved.

Unfortunately, the MT data along the profile 2a display a serious increase of the noise contamination towards the east, as more densely populated and industrialized areas are approached. This factor disqualifies some of the analysis procedures, especially the decomposition techniques, which are highly sensitive to the data quality.

The previous AMT measurements (Červ et al., 1997) had already indicated that there is a sudden change of the Swift's principal direction when crossing, in the W-E direction, the line coincident approximately with the Tachov fault, or its continuation to the north. To the west of that line, the orientation of the polar impedance diagrams is, according to their major axes, predominantly SW-NE to SSW-NNE, whereas to the east of the dividing line it is SE-NW to SSE-NNW. In Fig. 18a, this discontinuity is illustrated by plotting the principal axes of the polar impedance diagrams for periods 10 to $4096 \mathrm{~s}$ simultaneously at each site. The plot shows that the pattern remains almost unchanged in a broad range of periods, the AMT band included (not shown here).

Considering the worse quality of the MT data, it is difficult to decide whether the principal directions reflect the true structural strike, or express the distorting effect of shallower crustal inhomogeneities. Nevertheless, at some localities, despite the large data errors, the decomposition parameters display a reasonably consistent behaviour, and may indicate superposition effects in the MT data. In particular, this refers to the sites OSTR and HAJE on the profile 2, NEBL on the profile $2 \mathrm{a}$, and bSED and bTRI on the profile 1, where approximately the same estimates of the regional strike could be found, within the interval $\left(0^{\circ}, 20^{\circ}\right)$. At other stations the decomposition parameters vary largely, and do not allow us to make any conclusion with regard to a possible 


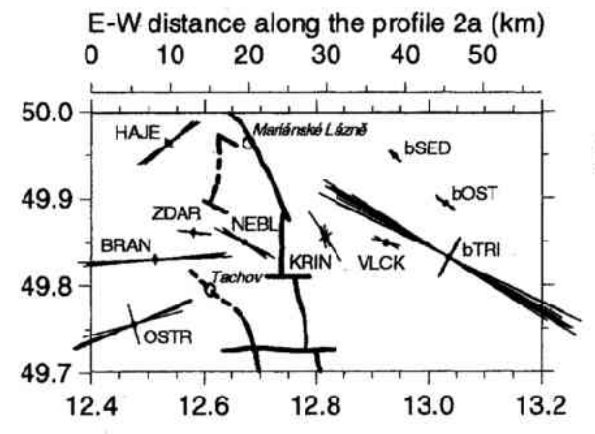

a)

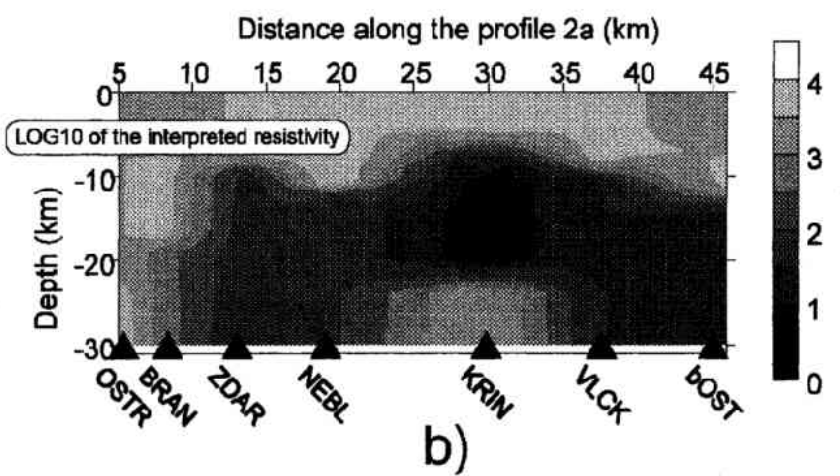

Fig. 18. a)-Principal axes of the polar impedance diagrams at the stations in the Tachov region for the period range from $10 \mathrm{~s}$ to $4096 \mathrm{~s}$. b) -Qualitative picture of the resistivity distribution along the profile 2a obtained by interpolating the 1-D inversions of the Berdichevsky determinant impedance at individual stations. Effects of distortions are not considered.

regional strike. The existence of a regional strike near to $90^{\circ}$ would be, however, in accord with the long period real induction arrows, which do not deviate substantially from the southward direction along the whole profile $2 \mathrm{a}$, in particular for very long periods.

In Fig. $18 \mathrm{~b}$ we present a qualitative picture of the resistivity distribution along the profile $2 \mathrm{a}$, obtained by $2-\mathrm{D}$ interpolating the $1-\mathrm{D}$ inversions of the Berdichevsky invariant impedance at the individual sites. In view of the decreasing anisotropy of the MT curves towards the east, we consider this approach justified as a first approximation. The resistivity seems to decrease progressively towards the east, reaching its local minimum at KRIN near to the Mariánské Lázně fault. High resistivities are observed in the upper crust below the whole central section of the subprofile, which corresponds to the highly resistive formations of the West Bohemian Pluton. The resistivity decrease towards the east fits well the data from the regional profile 1 . The particular zone P.2a of the profile 1 (see Fig. 16), where our sub-profile merges with the profile 1, represents a geologically complex area, with the resistivity drop explained by the increased fracturation and effect of mineralized water in a disturbed zone extending as far as the nearby Konstantinovy Lázně spa (Hudečková and Pícha, 1997).

\subsection{Magnetotelluric measurements along the sub-profile 2b, Kdynĕ region}

The sub-profile $2 \mathrm{~b}$, situated in the southern section of the regional profile 2 in SW Bohemia, consisted of 4 long period MT sites arranged approximately in the SW-NE direction, starting in the Kdyně ultrabasic complex and running along the Central Bohemian deep fault (Fig. 19). The profile represented a continuation of the AMT soundings performed earlier in the area involved by the Italian colleagues (Červ et al., 1997).

Geologically, the area of the profile $2 b$ is situated near the southern end of the West Bohemian paleorift, at the crossing of two prominent tectonic lines - the Bohemian Quartz Lode from the north and the Central Bohemian deep fault from the NE. Geophysically, the region represents a highly anomalous zone, with indications of large density contrasts within the crust. It is marked by large positive magnetic anomalies arranged along a SW-NE line running into the Bohemian Massif.

Along the profile $2 \mathrm{~b}$, the MT curves systematically indicate extremely low resistivities in the shallow crust. The mostly 3-D character of the data, without any significant indication as regards the decomposition possibilities, makes the estimates of the depth to the conductor unreliable, but 


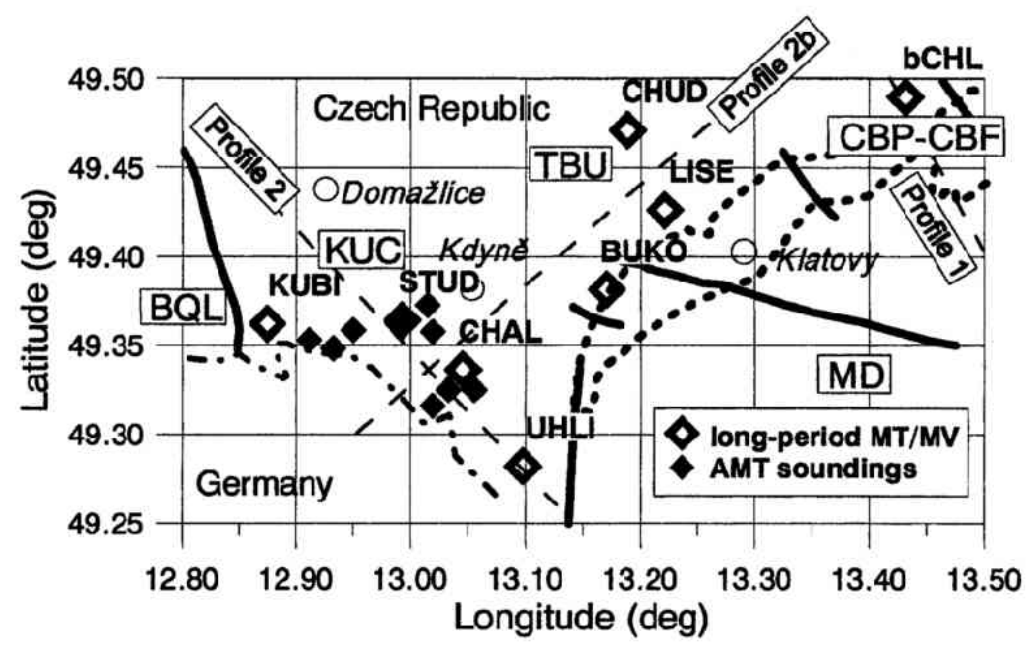

Fig. 19. Layout of the profile $2 \mathrm{~b}$ and the nearby stations on the regional profiles 1 and 2 in the Kdyner region. By boxes an approximate position of significant geological objects is indicated: BQL-Bohemian Quartz Lode, CBP-CBF-Central Bohemian Pluton and Central Bohemian deep fault, KUC-Kdyně ultrabasic complex, MD-Moldanubicum, TBU-Teplá-Barrandian Proterozoic unit.

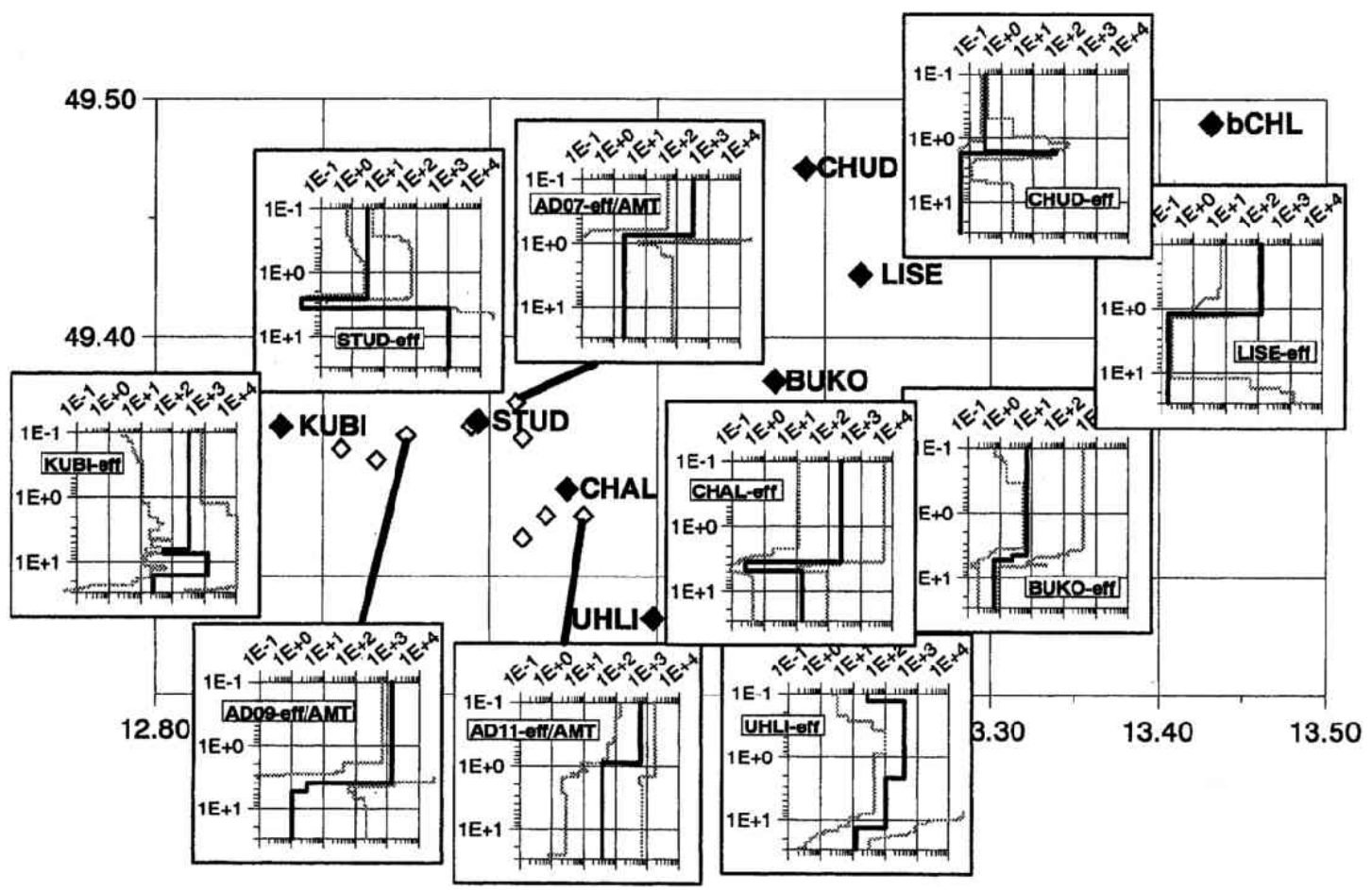

Fig. 20. Formal 1-D inversions of the effective apparent resistivities (Berdichevsky invariant) at selected stations from the area of the profile $2 \mathrm{~b}$. The 1-D model sections show the best fit model, as well as the maximum and minimum envelope of all the models of the test pool. 
in general the good conductor seems to emerge from the west to the east, from depths of a few $\mathrm{km}$ below the western section of the area to less than $1 \mathrm{~km}$ below the easternmost sites. Extreme situation is observed at the site CHUD, where apparent resistivities less than $1 \Omega \mathrm{m}$ were obtained in a wide range of periods. To give at least a qualitative idea about the resistivity distribution within the area involved, we present the 1-D interpretations of the effective MT curves (Berdichevsky invariant) at selected stations in Fig. 20. At the moment, we cannot present any further consistent results of a more complex, multidimensional modelling of that intricate region.

Towards the NE, the profile $2 \mathrm{~b}$ approaches the zone P.2b of the regional profile 1 (station bCHL, Fig. 19), where the resistivity drop is also observed, attributed to the transition zone from the Teplá-Barrandian unit to the South Bohemia Moldanubicum. The authors of the interpretation of the profile 1 (Hudečková and Pícha, 1997) suggest a hypothesis which tries to explain the extremely high conductivities at that contact zone by the presence of highly altered spilites. This alteration gives rise to the fine-grained pyrhotite and pyrite, which, together with fracturation, can increase the rock conductivity substantially. No quantitative verification of this hypothesis has been, however, presented, neither the regional extent of the proposed mechanism discussed.

\section{Conclusion}

The results presented in this contribution are a partial step to developing a consistent 3-D model of the geoelectrical structure of the western margins of the Bohemian Massif. With regard to the long-period data available, the conclusions can refer only to the large-scale features of the conductivity structure of the region. Nevertheless, they can be of interest in a region, which represents a complex geological contact of several first-order tectonic units within the western part of the Bohemian Massif. Moreover, an extensive geophysical and geological material for consequent comparative studies is available in the region involved, particularly from the KTB deep borehole area.

The principal conclusions of the long-period magnetotelluric investigations in W and SW Bohemia can be summarized as follows:

(1) The long period MT/GDS data along the profile 2 display striking similarity with those obtained in the close vicinity of the KTB area (Eisel, 1995; Tauber, 1993), with induction arrows directed predominantly to the south and large anisotropy of the MT impedances, indicating the direction of the highest conductivity to be NW-SE to NNW-SSE. This character of the MT anisotropy seems to be interrupted when crossing the West Bohemian fault zone towards the east, where the anisotropy generally decreases and changes to almost NE-SW. Relaxation of the impedance diagrams at the contact of an anisotropic structure and an isotropic medium might qualitatively explain such a directional change (Pek and Verner, 1997), but numerical models have so far failed to simulate that effect over a period range of several orders. The general decrease of the resistivity to the east of the West Bohemian faults conforms well with the generally indicated low-resistivity zone in the upper crust of the Teplá-Barrandian unit, interpreted along the regional profile 1 .

(2) The deep over-regional, E-W striking structure is characterized by a decreasing induction effect towards the south, resulting either from a gradually decreasing conductance of that structure, or from its abrupt termination somewhere to the north of the profile. To fit the MT phases, the former model of the over-regional structure is preferred, with the regional conductor represented by a relatively thin conductive layer at middle crustal depths, with gradually decreasing conductance towards the south. The question of the relation of this conducting layer to the detachment horizon, along which the crustal segments could separate and be stacked against the Franconian Line during the late Cretaceous (Duyster et al., 1995), is still under discussion (Eisel, 1995). 
(3) The large anisotropy of the MT impedances may be a combined effect of real macroanisotropy of the upper crustal layers, in the sense of Eisel's conductive dykes in the vicinity of the KTB (Eisel, 1994, 1995), and the static distortions of the MT curves. The MT data for longer periods, typically greater than several tens of seconds, support the composite model with the underlying regional structure characterized above, but for shorter periods the picture seems to be influenced by inductive effects. Moreover, the question of the composition of local distortions with a macro-anisotropic structure has not been solved yet.

(4) The area of the Central Bohemian deep fault and its crossing with the West Bohemian fault zone represents an electrically highly anomalous phenomenon, manifested by an extreme resistivity decrease, most likely in the shallow crust. The hypothesis of a combined effect of the spilite alteration and fracturation in that zone has been suggested in (Hudečková and Pícha, 1997) to explain the increased conductivities, has not been, however, given any quantitative support yet. Two MT stations at the southernmost end of the profile 2, as well as the stations south of the Central Bohemian Pluton on the profile 1, processed only preliminarily so far (Hudečková and Pícha, 1997), indicate generally lower resistivities beneath the Šumava and South Bohemia Moldanubicum as compared with those interpreted beneath the northern and central part of the profile 2 .

Unfortunately, a progressive increase of the level of the cultural noise in the MT data towards the east, into more densely populated and industrialized areas of West Bohemia, seems to be also one of the general conclusions of the induction studies in the western part of the Bohemian Massif. For the MT data from the profile 2a, e.g., the typical values of the MT error parameter $\varepsilon$ are 0.05 to 0.1 over the whole period range involved for the sites in the W (OSTR to NEBL), whereas values of 0.3 to 0.5 are not rare at the easternmost sites KRIN and VLCK, as well as at some nearby sites from the profile 1 , especially for periods greater than $100 \mathrm{~s}$.

In general, the close similarity of our MT data in SW Bohemia to those obtained on the German side of the KTB area is in favour of the idea of the structural continuity of the western margin of the Bohemian Massif throughout the region demarcated by the Franconian Line in the west and the West Bohemian fault zone in the east. This block is surrounded by units which display rather different resistivity conditions, and a more detailed 3-D treatment of the structures involved seems to be inevitable as a next step to explain all the geoelectrical observations consistently.

Various stages of this research were supported by the project No. 31213 of the Grant Agency of the Academy of Sciences of the Czech Republic, and projects No. 205/93/0409 and No. 205/95/1305 of the Grant Agency of the Czech Republic, granted to the Geophysical Institute of the Academy of Sciences of the Czech Republic.

\section{REFERENCES}

Bahr, K., To the composition of decompositions, in Proceedings of the Colloquy 'Electromagnetic Deep Investigations', Hornburg, 19-23 March 1990, edited by V. Haak and J. Homilius, pp. 87-106, Inst. of Meteorol. and Geophys., Univ. of Frankfurt/M., Geol. Survey of Lower Saxony, 1990 (in German).

Bahr, K., Geological noise in magnetotelluric data: a classification of distortion types, Phys. Earth Planet. Int., 66, 24-38, 1991.

Behr, H.-J., Linear crustal structures in the vicinity of the KTB locality, KTB-Report, 92-3, Geol. Survey of Lower Saxony, 3-82, 1992 (in German).

Červ, V., J. Pek, J. Pěčová, and O. Praus, Electromagnetic measurements in the vicinity of the KTB drill site. Part II: Magnetotelluric results, Studia Geophys. et Geodaet., 37, 168-188, 1993.

Červ, V., J. Pek, O. Praus, A. Zaja, and A. Manzella, Magnetotelluric and deep geomagnetic induction data in the Bohemian Massif, Annali di Geofisica, 40, No. 2, 413-422, 1997.

Duyster, J., A. Kontny, H. de Wall, and G. Zulauf, Postvariscan crustal stacking at the western margin of the Bohemian Massif, Geowissenschaften, 13, No. 4, 135-141, 1995 (in German).

Eisel, M., On the superposition of local and regional conductivity anomalies investigated with magnetotelluric 
measurements along a north-south profile in the northeast of Oberpfalz, Diploma Thesis, Inst. of Meteorol. and Geophys., Univ. of Frankfurt/M., 135 pp., 1990 (in German).

Eisel, M., An anisotropic model of the ZEV, in Proceedings of the Colloquy 'Electromagnetic Deep Investigations', Höchst im Odenwald, 28-31 March 1994, edited by K. Bahr and A. Junge, pp. 40-46, German Geophysical Society, 1994 (in German).

Eisel, M., Interpretation of magnetotelluric measurements in the vicinity of the Continental Deep Borehole with special attention to laterally anisotropic conductivity structures, Ph.D. Thesis, Scientific Technical Report STR95/13, GeoForschungsZentrum Potsdam, 118 pp., 1995 (in German).

Groom, R. W. and R. C. Bailey, Decomposition of the magnetotelluric impedance tensor in the presence of local three-dimensional galvanic distortion, J. Geophys. Res., 94 (B2), 1913-1925, 1989.

Haak, V., J. Stoll, and H. Winter, Why is the electrical resistivity around the KTB hole so low?, Phys. Earth Planet. Int., 66, 12-33, 1991.

Hofer, S., Determination of the electrical conductivity distribution in the earth crust in the area of the first-order tectonic boundary Rhenohercynicum-Saxothuringicum eastwards of the Rhine Graben by means of the joint interpretation of magnetotelluric and geomagnetic deep sounding array measurements, Ph.D. Thesis, Univ. of Munich, 155 pp., 1990 (in German).

Hudečková, E. and B. Pícha, Magnetotelluric soundings along the profile 9HR, in Geological Model of the Western Part of the Bohemian Massif in Relation to the Ultra-Deep Botehole (KTB) in the FRG, edited by S. Vrána, Czech Geol. Inst., Prague, 1997 (in press).

Jones, A. G. and R. W. Groom, Strike-angle determination from the magnetotelluric impedance tensor in the presence of noise and local distortion: rotate at your peril!, Geophys. J. Int., 113, 524-534, 1993.

Klause, R., K. Murasch, and G. Schwarz, Broad-band geomagnetic and magnetotelluric soundings in West Bohemia, in Proceedings of the Colloquy 'Electromagnetic Deep Investigations', Höchst im Odenwald, 28-31 March 1994, edited by K. Bahr and A. Junge, pp. 250-258, German Geophysical Society, 1994 (in German).

$\mathrm{Krs}$, M. and P. Pruner, Contribution of the complex interpretation of magnetic and palaeomagnetic data to the palaeogeography of blocks of the Bohemian Massif, in Crustal Structure of the Bohemian Massif and the West Carpathians, edited by V. Bucha and M. Blížkovský, pp. 228-233, Academia Prague in co-edition with Springer-Verlag, Berlin Heidelberg New York, 1994.

Martinez, M. M., Fundamentals of newer inversion procedures and their application to the 1-D inversion in the magnetotellurics, in Proceedings of the Colloquy 'Electromagnetic Deep Investigations', Taunus, 1-3 March 1988, edited by V. Haak and J. Homilius, pp. 97-107, Inst. of Meteorol. and Geophys., Univ. of Frankfurt/M., Geol. Survey of Lower Saxony, 1988 (in German).

Pek, J., Numerical inversion of 2D MT data by models with variable geometry, Phys. Earth Planet. Int., 45, 193-203, 1987.

Pek, J. and T. Verner, Finite difference modelling of magnetotelluric fields in 2-D anisotropic media, Geophys. J. Int., 128, 505-521, 1997.

Suk, M., M. Blížkovský, T. Buday, I. Chlupáč, I. Cicha, A. Dudek, J. Dvořák, M. Eliáš, V. Holub, J. Ibrmajer, O. Kodym, Z. Kukal, M. Malkovský, E. Menčík, V. Müller, J. Tyráček, Z. Vejnar, and A. Zeman, Geological History of the Territory of the Czech Socialist Republic, pp. 17-33, Geolog. Survey Prague, Academia Prague, 1984.

Tauber, S., The conductivity distribution in the northern Variscides investigated by the magnetotelluric and geomagnetic deep sounding method along a profile from the Oberpfälzer Wald to Vogtland, Diploma Thesis, Inst. of Geol., Geophys. and Geoinform., Free Univ. of Berlin, 102 pp., 1993 (in German). 